Florida International University

FIU Digital Commons

$11-14-2019$

\title{
The Applications of Intumescent Technologies in Support of D\&D Activities Across The DOE Complex
}

Joshua Alan Nunez

Florida International University, jnune097@fiu.edu

Follow this and additional works at: https://digitalcommons.fiu.edu/etd

Part of the Heat Transfer, Combustion Commons

\section{Recommended Citation}

Nunez, Joshua Alan, "The Applications of Intumescent Technologies in Support of D\&D Activities Across The DOE Complex" (2019). FIU Electronic Theses and Dissertations. 4316.

https://digitalcommons.fiu.edu/etd/4316

This work is brought to you for free and open access by the University Graduate School at FIU Digital Commons. It has been accepted for inclusion in FIU Electronic Theses and Dissertations by an authorized administrator of FIU Digital Commons. For more information, please contact dcc@fiu.edu. 


\section{FLORIDA INTERNATIONAL UNIVERSITY}

Miami, Florida

\section{THE APPLICATIONS OF INTUMESCENT TECHNOLOGIES IN SUPPORT OF D\&D ACTIVITIES ACROSS THE DOE COMPLEX}

A thesis submitted in partial fulfillment of the

requirements for the degree of

MASTER OF SCIENCE

in

MECHANICAL ENGINEERING

by

Joshua Alan Nuñez

2019 
To: Dean John L. Volakis

College of Engineering \& Computing

This thesis, written by Joshua Alan Nuñez, and entitled The Applications of Intumescent Technologies in Support of D\&D Activities across the DOE Complex, having been approved in respect to style and intellectual content, is referred to you for judgment.

We have read this thesis and recommend that it be approved.

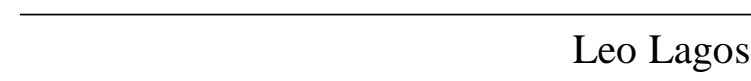

Leo Lagos

Yiding Cao

Andres Tremante, Major Professor

Date of Defense: November 14, 2019

The thesis of Joshua Alan Nuñez is approved.

Dean John L. Volakis College of Engineering \& Computing

Andrés G. Gil

Vice President for Research and Economic Development and Dean of the University Graduate School

Florida International University, 2019 


\section{ACKNOWLEDGMENTS}

I would like to acknowledge and offer my sincere gratitude to all who contributed to the work presented in this thesis. Specifically, I would like to thank my mentor at the Applied Research Center Mr. Joseph Sinicrope, and my advisor Dr. Leonel Lagos. Mr. Sinicrope's mentoring went above and beyond the importance of this work and how to improve upon it, and he has nonetheless always paved for me a clear path to success. He has helped me to remain focused and stay on track, I would have undoubtedly been lost without his guidance. I am also very thankful to Dr. Lagos for allowing me to become a DOE Fellow as it has granted the knowledge and experience necessary to advance my career. Last, but certainly not least, I would like to thank my family for supporting me throughout my academic career. I would not be where I am today if it weren't for these people. 


\title{
ABSTRACT OF THE THESIS \\ THE APPLICATIONS OF INTUMESCENT TECHNOLOGIES IN SUPPORT \\ OF D\&D ACTIVITIES ACROSS THE DOE COMPLEX
}

\author{
by
}

Joshua Alan Nuñez

Florida International University, 2019

Miami, Florida

Professor Andres Tremante, Major Professor

Nuclear facilities in the process of Deactivation and Decommissioning (D\&D) face several enormous challenges. Decommissioning is only part of the final shutdown process of a nuclear facility. The majority of the DOE facilities, like most industries, face fire hazards or extreme heat conditions. This study aims to research, test, and validate the operational performance of commercially available polyurethane expanding intumescent foams as potential fixatives for immobilizing residual contamination while preserving fire resiliency. Due to the novelty of this unique problem set and approach, existing international standards (ASTM/NIST/etc.) were reviewed for best-fit platforms with which to build testing protocols from. Once the test methods were implemented in a laboratory setting, results and data generated were reviewed by SRNL personnel.

The conclusion of this research resulted in establishing a safe and viable nondestructive evaluation method for detecting inconsistencies and anomalies in the application and foam curing process, which will lead to a more successful implementation of intumescent foam in areas that would otherwise be difficult to assess and increase the safety of workers and the environment within the DOE nuclear complex. 


\section{TABLE OF CONTENTS}

CHAPTER

PAGE

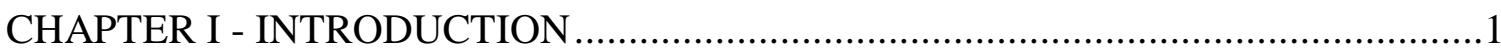

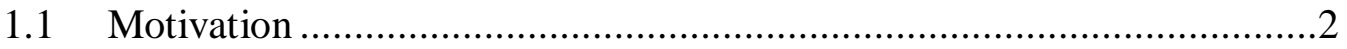

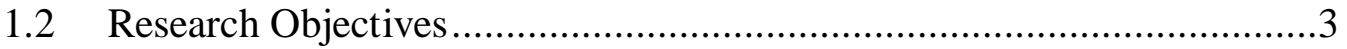

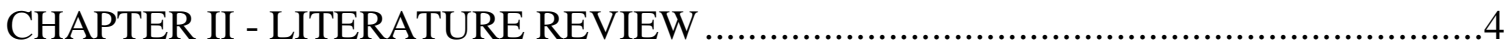

2.1 Review of Intumescent Technologies .................................................

2.2 Review of Polyurethane Foams ..........................................................

CHAPTER III - PROCEDURES AND METHODS ……........................................

3.1 Baselining of Existing Polyurethane Foams …………...........................

3.1.1 The Flammability Classification ..................................................

3.1.2 2-Hour Direct Flame Exposure ………………................................11

3.1.3 Incremental Temperature Experiment ............................................11

3.2 Curing Temperature Profile Experiment....................................................13

3.3 Uniformity of Curing/Initial Proof-of-Concept .......................................14

$3.4 \quad$ Non-Destructive Evaluation (NDE) Method..........................................16

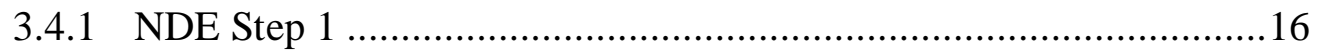

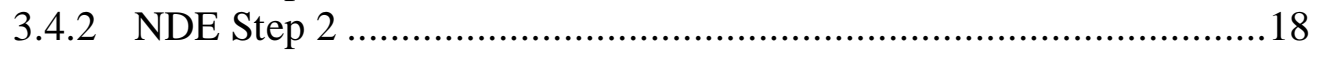

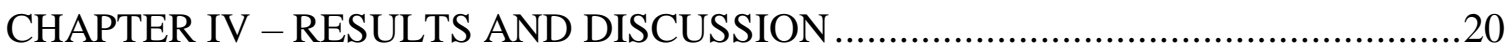

4.1 Baselining of Existing Polyurethane Foams ………...............................20

4.1.1 The Flammability Classification ……………............................20

4.1.2 2-Hour Direct Flame Exposure ……………...............................25

4.1.3 Incremental Temperature Experiment ..............................................26

4.2 Curing Temperature Profile Experiment ..............................................28

4.3 Uniformity of Curing/Initial Proof-of-Concept …………………...........29

4.4 Non-Destructive Evaluation (NDE) Method..........................................31

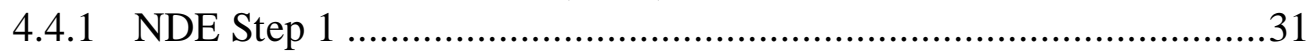

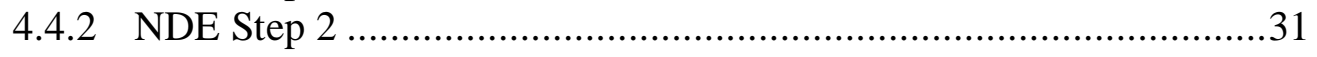

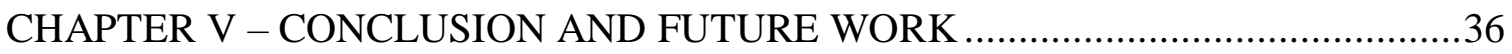

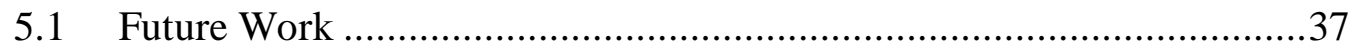

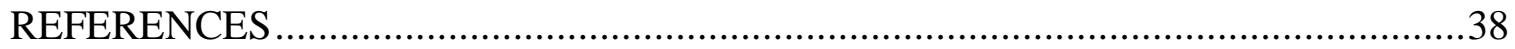




\section{LIST OF TABLES}

TABLE

PAGE

Table 1. IEC 60695-11-10 - Vertical Test Results ....................................................21

Table 2. IEC 60695-11-10 - Horizontal Test Results; after one trial ............................22

Table 3. Median Mass Loss of Foam Samples ....................................................2

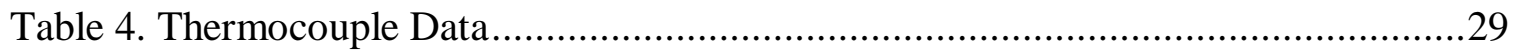

Table 5. Average Temperatures from Thermal Images..............................................34 


\section{LIST OF FIGURES}

FIGURE

PAGE

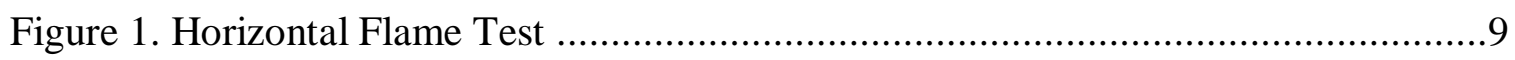

Figure 2. Experimental Setup of Horizontal Flame Test ................................................9

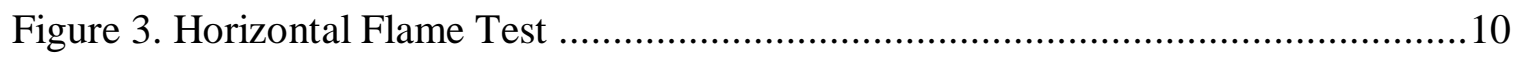

Figure 4. Experimental Setup of Vertical Flame Test ..................................................10

Figure 5. Experimental Setup of 2-Hour Direct Flame Exposure.....................................11

Figure 6. Setup of Incremental Temperature Experiment ………..................................12

Figure 7. Extech TP870: Bead Wire Type K Temperature Probe ……..............................13

Figure 8. Extech SDL200: 4-Channel Datalogging Thermometer..................................14

Figure 9. Experimental setup of polystyrene containers with a thermocouple ..................14

Figure 10. Clear PVC pipe with eight (8) thermocouples inserted along its length..........15

Figure 11. Internal Thermocouples (NDE Step 1) ……….....................................17

Figure 12. Externally Placed Thermocouples (NDE Step 1) .........................................17

Figure 13. FLIR E53 Advanced Thermal Imaging Camera ……………….................18

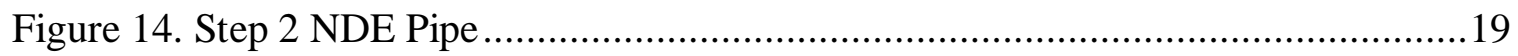

Figure 15. Testing of Non-Fire Rated Foam Samples..................................................23

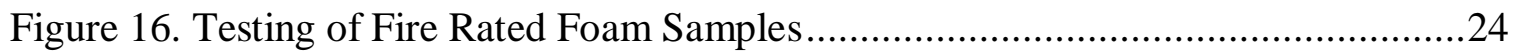

Figure 17.Testing of Intumescent Foam Samples ....................................................25

Figure 18. Dissected Intumescent Foam Samples; Hilti(left) and 3M(right) ..................26

Figure 19. Total Mass Loss of Foam Samples ............................................................2

Figure 20. Polystyrene Containers Filled with Hilti Intumescent Foam .........................28

Figure 21. Curing Temperature Profile of Hilti Intumescent Foam...............................28 
Figure 22. Initial Proof-of-Concept Result

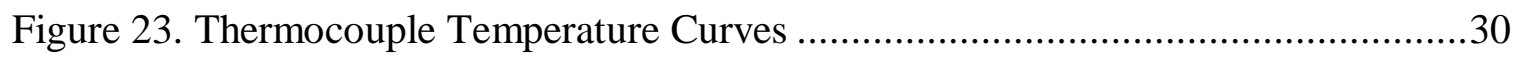

Figure 24. Step 1 NDE Snapshot from FLIR Thermal Imaging Camera ........................31

Figure 25. Side-by-side Comparison of Thermal Image and Normal Image ..................32

Figure 26. Thermal image Undergoing Visual Analysis with FLIR Software ................32

Figure 27. Measurements boxes in FLIR software for gathering numerical data.............33

Figure 28. Temperature vs. Time Plot of Measurement Boxes ..................................35

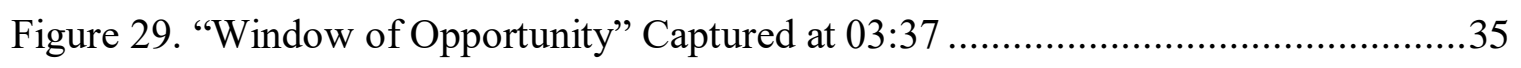




\section{CHAPTER I - INTRODUCTION}

Few situations are of greater concern during the Decommissioning \& Deactivation (D\&D) and interim storage activities than the possibility of a fire. Since the tragic events of the 9/11 terrorist attacks, there have been extensive developments in the area of intumescent technologies as a viable means of fire protection. As evidenced by the incident at Waste Isolation Pilot Plant (WIPP) in February 2014, and other sites across the Department of Energy (DOE) (Nelson, Patterson, \& VanLuik, 2015) and international nuclear complexes, the potential for a release of radioactive contaminants when exposed to fire is ever-present. In addition, many of the fixative technologies in common use during the D\&D of facilities are highly vulnerable to fire and extreme heat conditions, thereby increasing the risk of a release of the radioactive contaminants, resulting in potential exposure to workers and the general public (Nicholson \& Velten, Evaluation of Environmental Conditions on the Curing Of Commercial Fixative and Intumescent Coatings, 2017). The basis for interim operation (BIO) in support of SRS 235-F contains a postulated accident scenario where an earthquake causes a breach of the facility containment structure. This seismic event is also postulated to initiate a large room fire that could propagate and potentially evolve into a full facility fire that engulfs the material at risk (MAR), such as residual $\mathrm{Pu}-238$ and $\mathrm{Np}-237$, causing it to be released from the building and become airborne. This contingency scenario and other fire-related events across the various sites have prompted a requirement for fire retardant/fire protection technologies that can enhance a facility's overall fire protection posture and mitigate the release of radioisotopes during these emergencies. 


\subsection{Motivation}

Nuclear facilities that are moving towards final disposition, face enormous challenges to ensure no holdup material, the accumulation of special nuclear material inside the processing equipment of nuclear facilities (Los Alamos National Laboratory, Operated by Los Alamos National Security, LLC, for the U.S. Department of Energy, 2019), is released to the environment between the times the facility is no longer active through final disposition. Workers actively seek to remove as much of the radioactive materials holdup as possible; however, current decontamination methods are not effective in the removal of all contaminated material. As such, for contaminated areas, there is often some residual contamination remaining after material removal and decontamination efforts have concluded. Gloveboxes are a particular source of holdup contamination that must be addressed, as they are numerous in legacy nuclear facilities.

Initially developed to protect and insulate various substrates from extreme heat and fire conditions to maintain their structural integrity, research revealed that in certain instances the fire protection was so effective that it protected the primer itself on the substrate. ARC scientists have had firsthand knowledge and experience in the use of intumescent technologies to harden facilities and improve fire protection in support of the U.S. military, and in close collaboration with researchers at Savannah River National Lab (SRNL), explored the feasibility of using the technology to address the Department of Energy's Office of Environmental Management's (DOE-EM) stated requirement for incombustible fixatives in support of Deactivation \& Decommissioning (D\&D) activities. The potential application to several of the most pressing challenges are evident, specifically 
improving the overall fire protection posture and decreasing the at-risk nuclear material load within the safety basis of the facility, and continued research and development to adapt the technology to the radioactive environment encountered at SRS 235-F PuFF Facility.

\subsection{Research Objectives}

The primary focus of this thesis is to expand the research of adapting intumescent technologies to serve as radiological fixatives, specialized coatings used to fixate and immobilize radioactive isotopes and materials to surfaces (Demmer, Fox, Reese, Banford, \& Dodds, 2017). Perform testing and evaluation of intumescent technologies to enhance the stabilization of radioactive contamination and fire resiliency and protection for fixatives and facilities in support of D\&D activities across the globe, but more specifically across the DOE-EM complex. 


\section{CHAPTER II - LITERATURE REVIEW}

Although both research objectives of this thesis address issues of adapting intumescent technologies as radiological fixatives and improving their capacity to resist thermal stressors, for the sake of organization it is useful to separate the two topics as they are different.

\subsection{Review of Intumescent Technologies}

Fire is a serious threat to people and the structures they build. There is a continuous development of newer methods and materials to prevent the effects of thermal stressors. Today, a lot of attention is being placed in the design of public, commercial, and federallyowned buildings and structures by incorporating fire safety measures. Conventional passive fireproofing materials include paint, gypsum board, and cementitious coatings (Khanna \& Puri, 2016). The use of fire-retardant coatings is one of the easiest, one of the most efficient and one of the oldest ways to protect material against fire. It does indeed, present several advantages; it does not modify the intrinsic properties of the material(s) (e.g. mechanical properties), may be used on a multitude of materials such as polymers, wood, textiles, and metals, and it is easily processed. However, since ignition usually occurs on the surface of the material it is important to focus the protective action at this location (Duquesne, Magnet, Jama, \& Delobel, 2004). The protection of metallic materials against fire has become an important issue, as fire can warp and distort such materials which ultimately lead to a loss of structural integrity (Duquesne, Magnet, Jama, \& Delobel, 2004). 
Fire retardant coatings, acting by the phenomenon of intumescence, form on heating an expanding multicellular layer, which acts as a thermal barrier. It prevents heat from penetrating and flames from spreading when heated beyond its critical temperature. As a consequence, the result of this process is a foamed cellular charred layer on the surface which protects the underlying material from the action of the heat flux or flame. This insulative barrier makes intumescent coatings particular suitable for the protection of structural steel (Bourbigot, Le Bras, Duquesne, \& Rochery, 2004).

\subsection{Review of Polyurethane Foams}

Polyurethanes are a broad range of polymers, which are formed from the reactions between isocyanates (diisocyanates and polyisocyanates) with diols or polyols. According to the types, amounts of these ingredients and overall reaction circumstances, products such as flexible foams, rigid foams, elastomers, adhesives, and coatings are produced. Since polyurethane products, especially foams, play such an indispensable role in our daily lives because of their wide range of applications, reducing the fire risk of such products becomes more vital (Gharehbagh \& Ahmadi, 2012).

Rigid polyurethane foams have been used in various industrial fields such as construction, transportation, refrigeration, and chemical pipelines. Due to their excellent thermal insulation, low density, high specific strength, good dimensional stability, and adhesion strength, they have become very attractive high-performance materials for offering numerous applications (Yang, Hu, Xu, Song, \& Li, 2015). Since the limiting oxygen index (LOI) of rigid polyurethane foam is around $17-19 \%$, this means that once they start to burn, it will not be self-extinguishing and flame propagation will happen very 
quickly due to their foam structure. In this case, the use of flame retardants to reduce combustibility and smoke propagation from polyurethane foams after ignition becomes very important (Yang, $\mathrm{Hu}, \mathrm{Xu}$, Song, \& Li, 2015). 


\section{CHAPTER III - PROCEDURES AND METHODS}

\subsection{Baselining of Existing Polyurethane Foams}

The objective to test and evaluate the flammability characteristics of commercialoff-the-shelf (COTS) foams through standardized testing in order to determine their resistance to thermal stressors was accomplished by using a flammability classification test in accordance with IEC 60695-11-10, a 2-hour long exposure to direct flame test, and a mass loss test by subjecting the foam samples to incremental temperature increases inside a muffle furnace.

For this series of experiments, the foam samples were prepped and shipped by researchers at SRNL to the testing site at FIU's Applied Research Center. The samples included six commercially available foam materials: two (2) non-fire rated, two (2) firerated, and two (2) intumescent products.

\subsubsection{The Flammability Classification}

The Flammability Classification - IEC 60695-11-10 specifies small-scale laboratory test procedures intended to compare the burning behavior of different materials used in electrotechnical products when vertically or horizontally oriented test bar specimens are exposed to a small flame ignition source (i.e. propane torch) with a nominal thermal power of $50 \mathrm{~W}$. These test methods are used to determine either the linear burning rate or the self-extinguishing properties of materials. These test methods apply to solid and

cellular materials that have an apparent density of more than $250 \mathrm{~kg} / \mathrm{m}^{3}$ (International Electrotechnical Commission (IEC), 2013). This test method is widely accepted throughout 
the industry as being a critical indicator that quantifiably establishes the flammability characteristics of plastics. And it should be noted that polyurethanes are not classified as plastics, however, they do exhibit similar properties. Though not specifically developed to test and evaluate polyurethane foams and their resistance to thermal stressors, the IEC 60695-11-10 Flammability Classification has been identified as a potential "near-fit" standard after extensive discussions between FIU and SRNL researchers (Sinicrope, Shoffner, Viera, Nuñez, \& Simoes-Ponce, 2018).

The flammability classification is comprised of two testing methods. Method A is a horizontal burning test and is intended to determine the linear burning rate of materials under specific test conditions. Method B is a vertical burning test and is intended to determine whether materials self-extinguish under specific test conditions (International Electrotechnical Commission (IEC), 2013).

\section{Method A-Horizontal Test Procedures}

- A specimen is supported in a horizontal position and is tilted at $45^{\circ}$. A flame is applied to the end of the specimen for 30 seconds or until the flame reaches the 1-inch mark. If the specimen continues to burn after the removal of the flame, the time for the specimen to burn between the 1- and 4-inch marks are recorded. If the specimen stops burning before the flame spreads to the 4-inch mark, the time of combustion and damaged length between the two marks is recorded. Three specimens are tested for each thickness (International Electrotechnical Commission (IEC), 2013). 


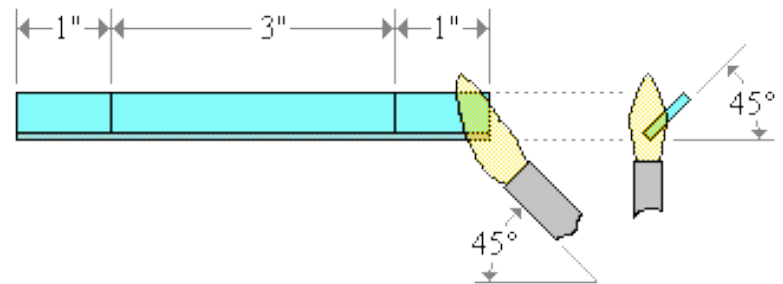

Figure 1. Horizontal Flame Test; intended to determine the linear burning rate of the specified material

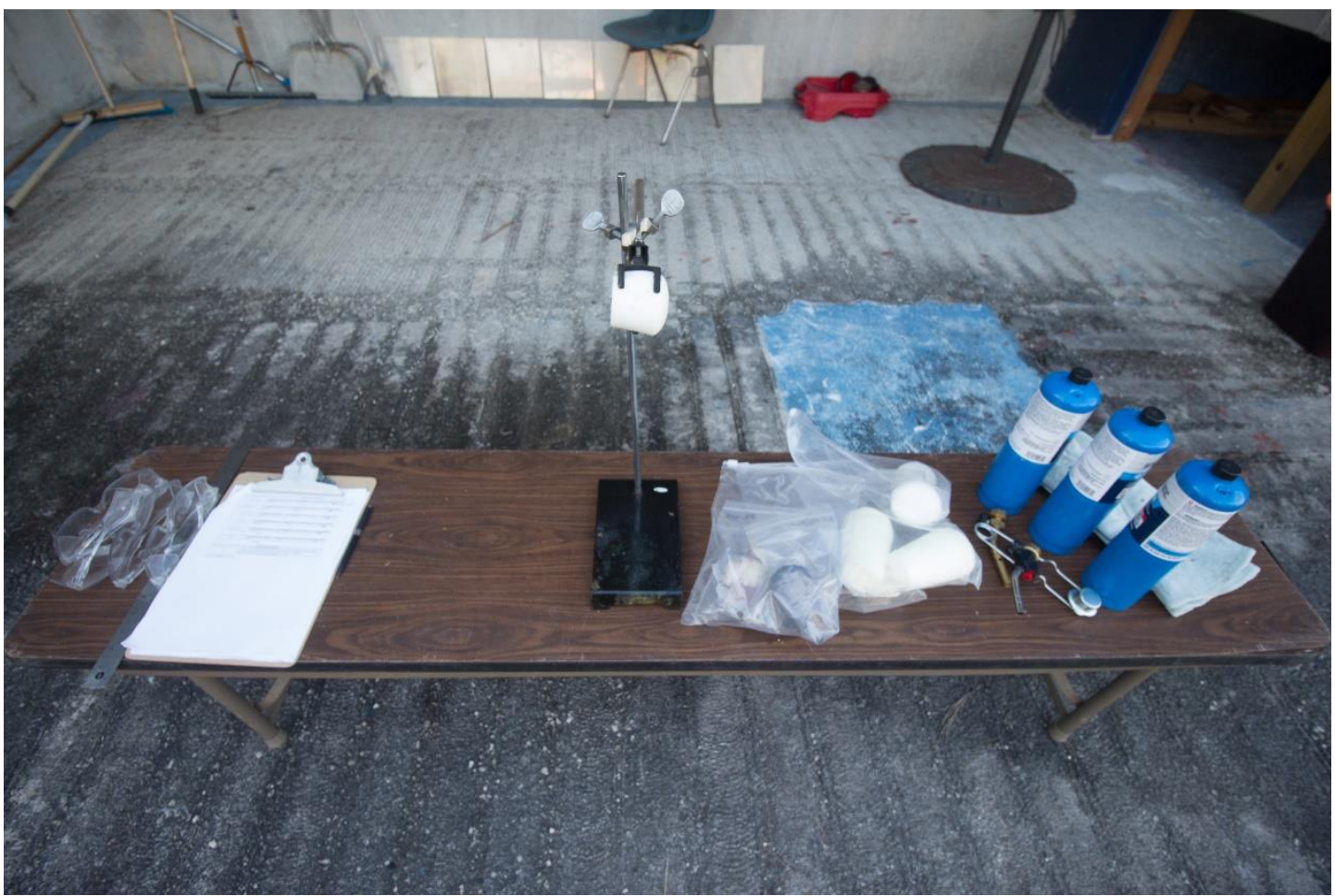

Figure 2. Experimental Setup of Horizontal Flame Test; Method A of the IEC 60695-11-10 Flammability Classification being conducted at the FIU-ARC outdoor testing area

2. Method B - Vertical Test Procedures

- A specimen is supported in a vertical position and a flame is applied to the bottom of the specimen. The flame is applied for ten seconds and then removed until flaming stops at which time the flame is reapplied for another ten seconds and then removed. Two sets of five specimens are tested. The 
two sets are conditioned under different conditions (International

Electrotechnical Commission (IEC), 2013).

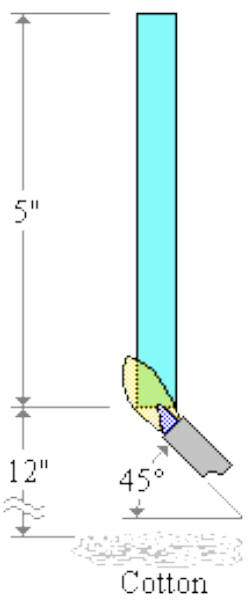

Figure 3. Horizontal Flame Test; intended to determine whether materials self-extinguish under specific test conditions

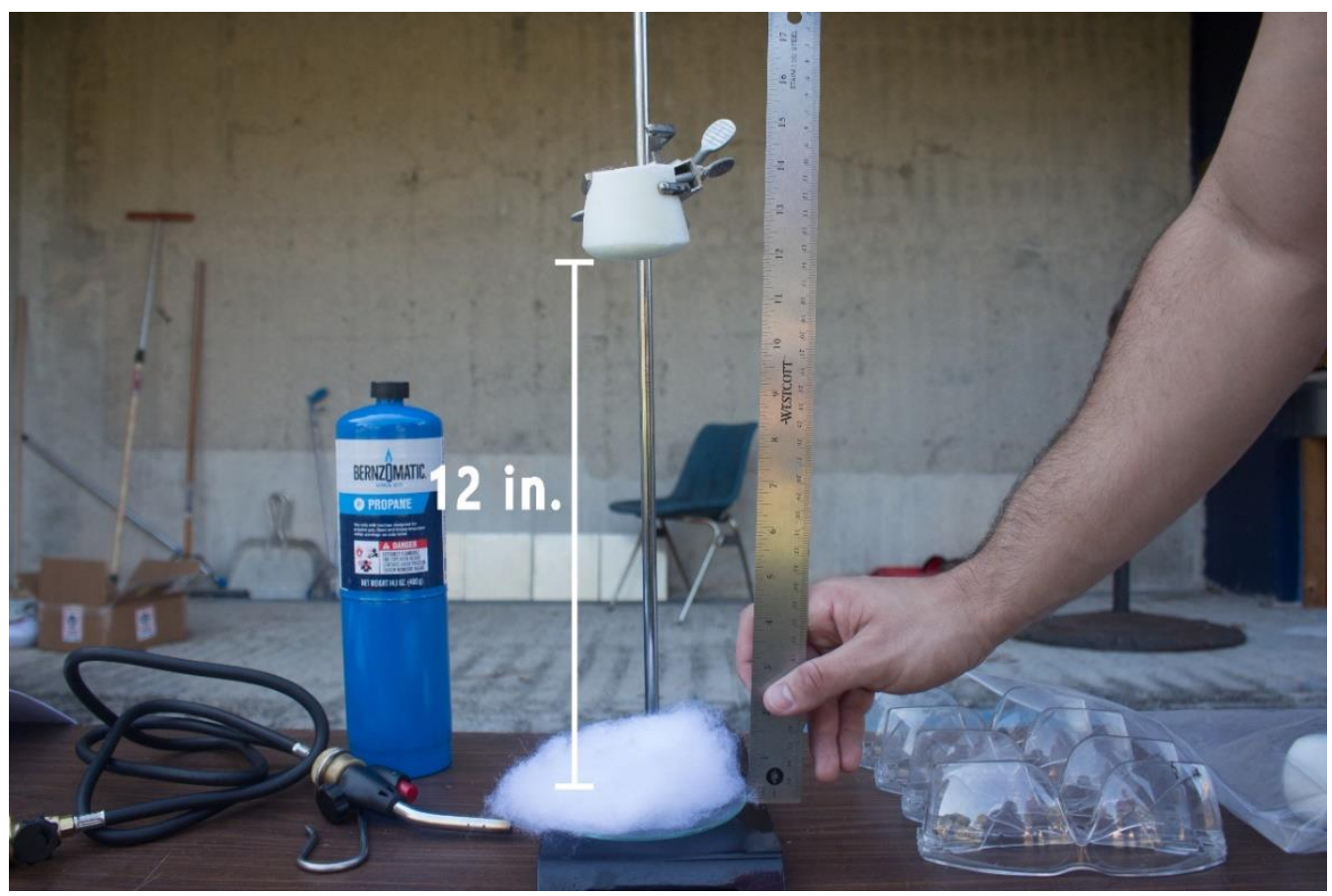

Figure 4. Experimental Setup of Vertical Flame Test; Method B of the IEC 60695-11-10 Flammability Classification being conducted at the FIU-ARC outdoor testing area 


\subsubsection{2-Hour Direct Flame Exposure}

This experiment was developed by FIU researchers, and modeled after the fire basis requirements of the Savannah River Site 235-F Facility.

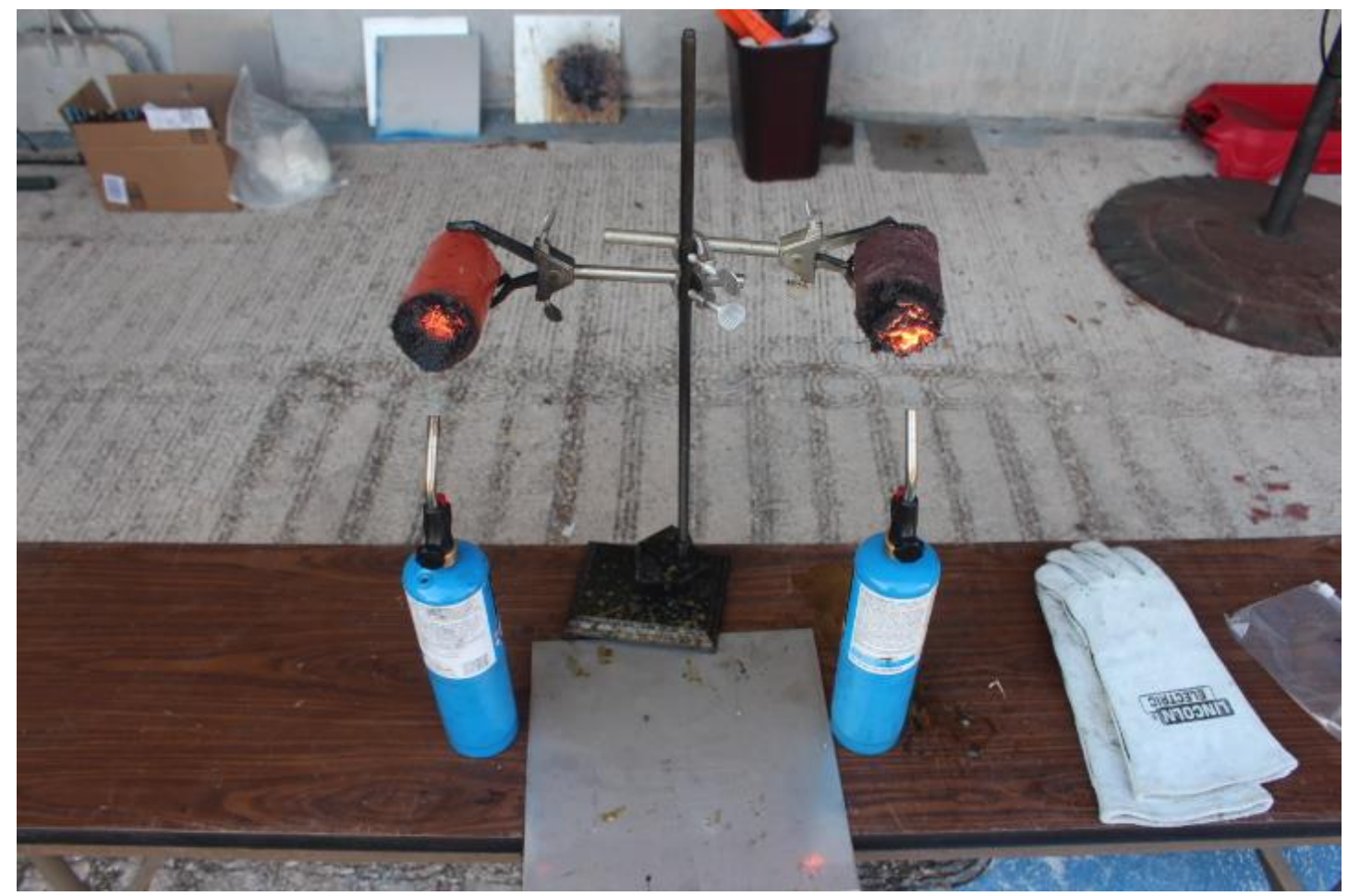

Figure 5. Experimental Setup of 2-Hour Direct Flame Exposure; intended to more closely align with the safety and fire basis requirements of the SRS 235-F facility.

\subsubsection{Incremental Temperature Experiment}

The objective of this test is to evaluate the mass loss that occurs to the foam samples when exposed to incremental temperature increases inside a muffle furnace for a designated time. Testing composite elements using furnaces of different sizes is a prevalent method to assess the effectiveness of intumescent coatings. Past researchers have exposed a large variety of tests samples to the standard temperature-time curve in furnaces, from bench scale to large scale (Lucherini \& Maluk, 2019). Some researchers have also shown 
that slow-growing fires or low heating regimes may cause an incomplete swelling of the reactive coating, or even facilitate melting and/or delamination. These phenomena can harm the overall effectiveness of the intumescent product (Lucherini \& Maluk, 2019).

\section{Experimental Procedures:}

○ Weigh polyurethane foam samples using an analytical laboratory scale before subjecting each foam sample to incrementally increasing temperatures (i.e.; $200^{\circ} \mathrm{F}, 300^{\circ} \mathrm{F}, 400^{\circ} \mathrm{F}, 500^{\circ} \mathrm{F}, 600^{\circ} \mathrm{F}, 700^{\circ} \mathrm{F}$, and $800^{\circ} \mathrm{F}$ ) in a muffle furnace for a time of 15 minutes per incremental temperature. The foam sample will have a 15-minute cooling period between each incremental temperature round, in which the sample will be re-weighed, and mass loss calculations performed. Follow the same procedure for all polyurethane foam samples except the $3 \mathrm{M}$ and Hilti samples. The $3 \mathrm{M}$ and Hilti samples will only be tested using the IEC 60695-11-10 flammability test that was discussed due to only having one sample of each.

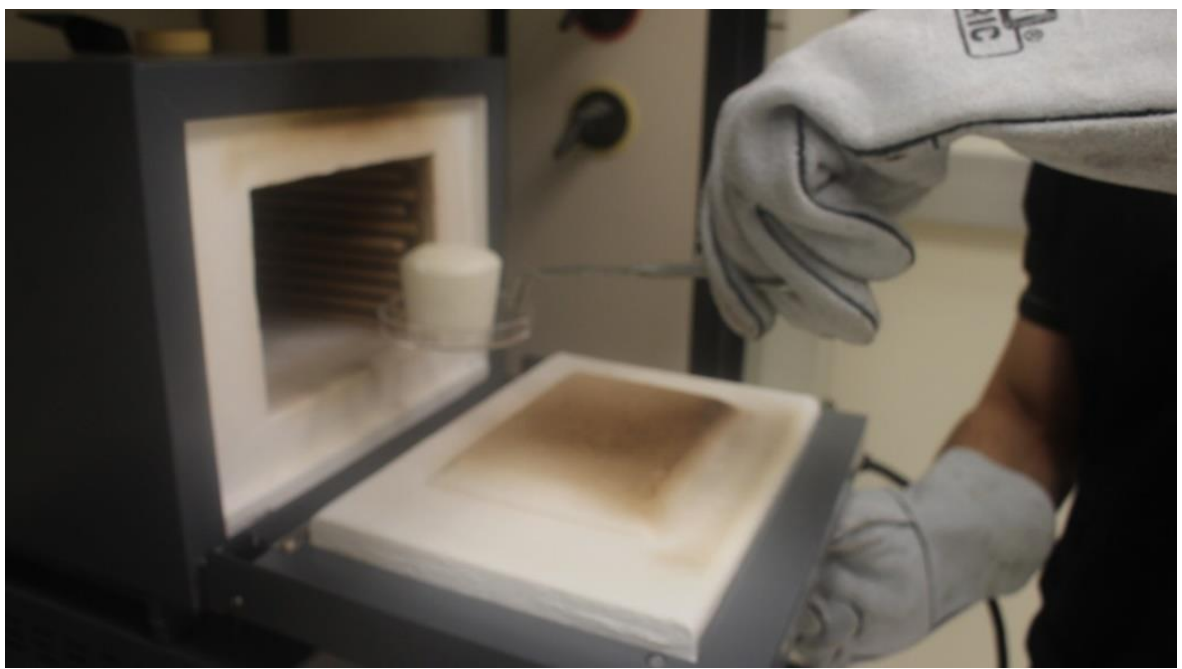

Figure 6. Setup of Incremental Temperature Experiment; intended to determine structural integrity and mass loss after exposure to incrementally rising temperatures 


\subsection{Curing Temperature Profile Experiment}

For the objective of determining the temperature profile during the curing process of the down-selected COTS foam, a foam sample was employed by filling a series of polystyrene containers (figure below) with a volume of $20 \mathrm{in}^{3}$. The polystyrene containers will each be retrofitted with a thermocouple at its center to ensure a proper temperature reading of the cured foam sample. The thermocouple is used for this experiment is the Extech TP870 Bead Wire Type K Thermocouple (figure below), which has a temperature range from $-40^{\circ} \mathrm{F}$ to $482^{\circ} \mathrm{F}$ (Extech, A FLIR Company, 2015). The temperature readings from the thermocouples will be registered and stored within the Extech SDL200 4-Channel Datalogging Thermometer (figure below). The Extech SDL200 can store 99 readings manually and 20 million readings via an SD card. When using Type K thermocouple, the Extech SDL200 is accurate within $\pm 0.4 \%$ of the temperature reading (Extech, A FLIR Company, 2015b). This experimental setup was designed to aid in determining the minimum and maximum temperature range of the foam curing process.

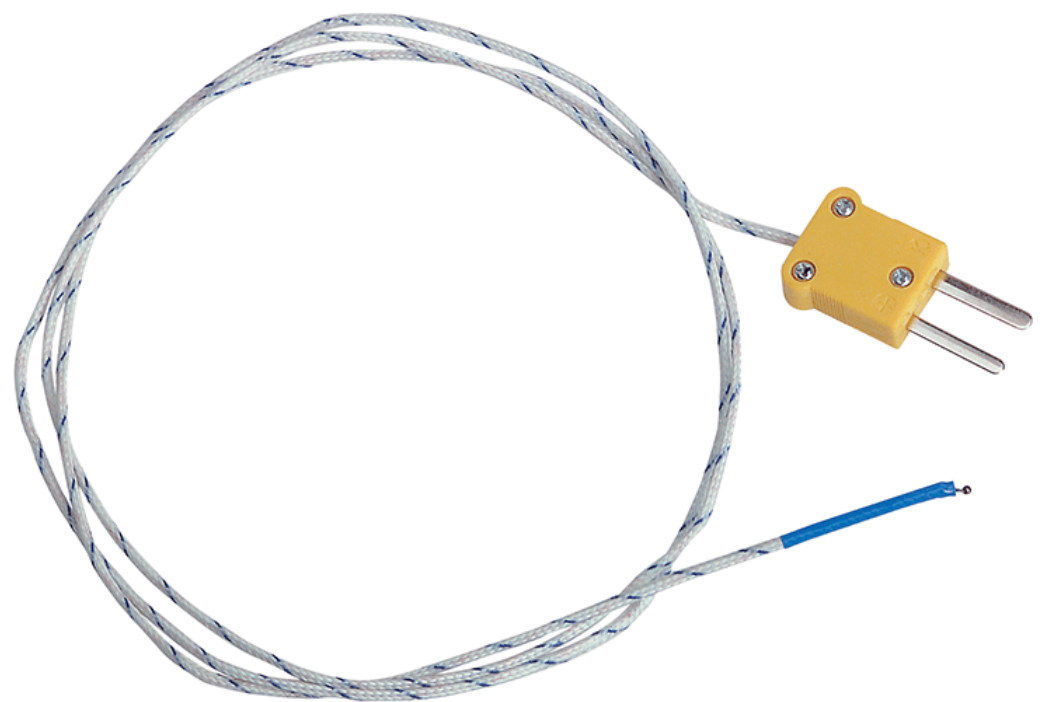

Figure 7. Extech TP870: Bead Wire Type K Temperature Probe; thermocouples used throughout experimentation 


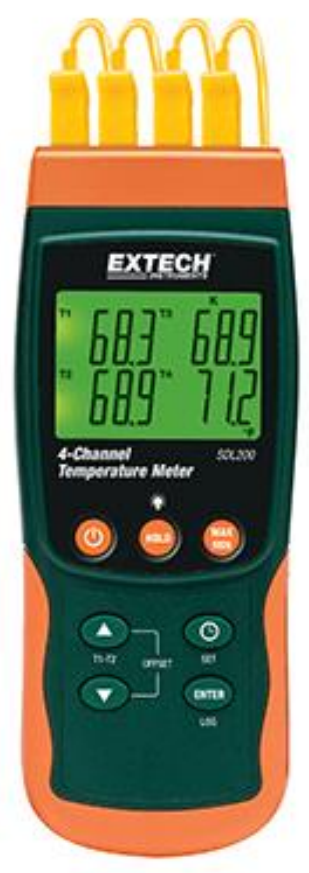

Figure 8. Extech SDL200: 4-Channel Datalogging Thermometer; datalogging equipment used in conjunction with the Extech TP870 thermocouples

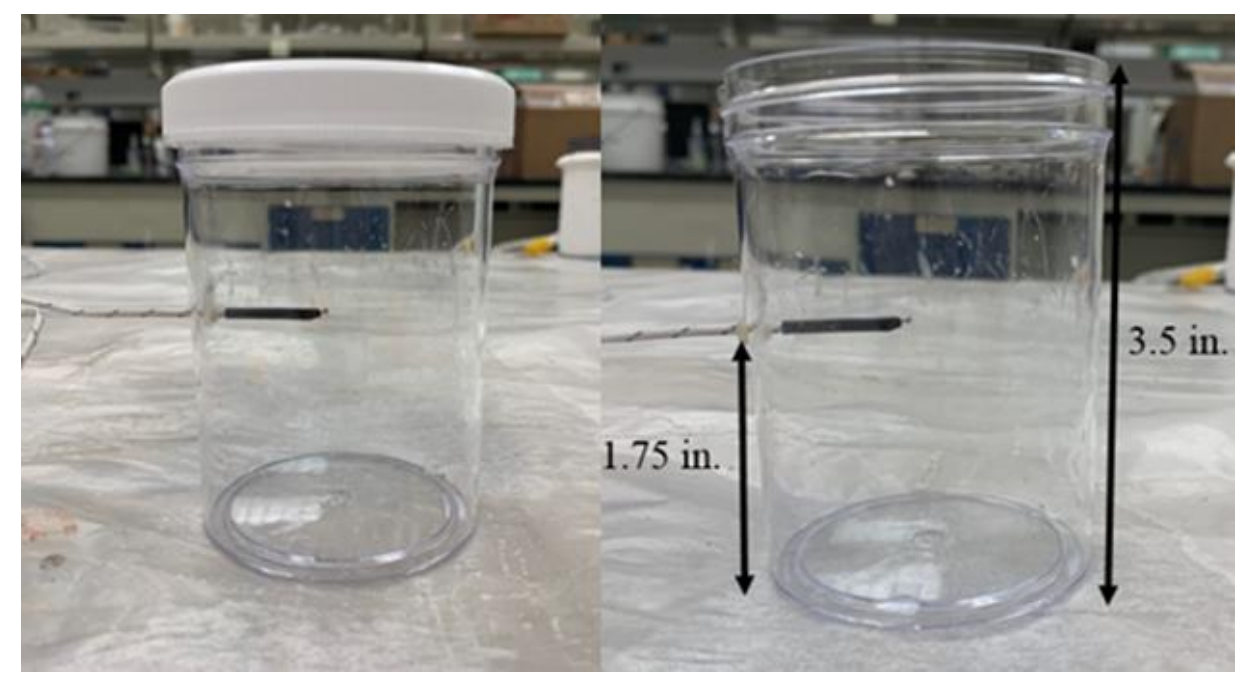

Figure 9. Experimental setup of polystyrene containers with a thermocouple

\subsection{Uniformity of Curing/Initial Proof-of-Concept}

For the objective to begin investigating the hypothesis stating that there is a correlation between temperature profile and inconsistencies in the application and/or foam 
curing process. The idea emerged that the temperature profile could also be an indicator of application and/or uniform curing.

Initial assessments on the viability of using temperature profile as a non-destructive means to determine inconsistencies in the application and/or foam curing process will be performed in a bench-scale experiment.

Experimental Design/Procedures:

- The experimental design to test the above-stated hypothesis includes a clear PVC pipe (12 inches long and 2.85 inches in diameter) and eight (8) Type $\mathrm{K}$ thermocouples evenly spread along its length. The thermocouples will be inserted at varying heights with thermocouples 3, 4, and 6 purposely exposed to simulate voids/artificialities to evaluate and test the hypothesis. Two (2) Extech SDL200 datalogging thermometers will be used to read and record temperatures with a sampling rate of $1 /$ second.

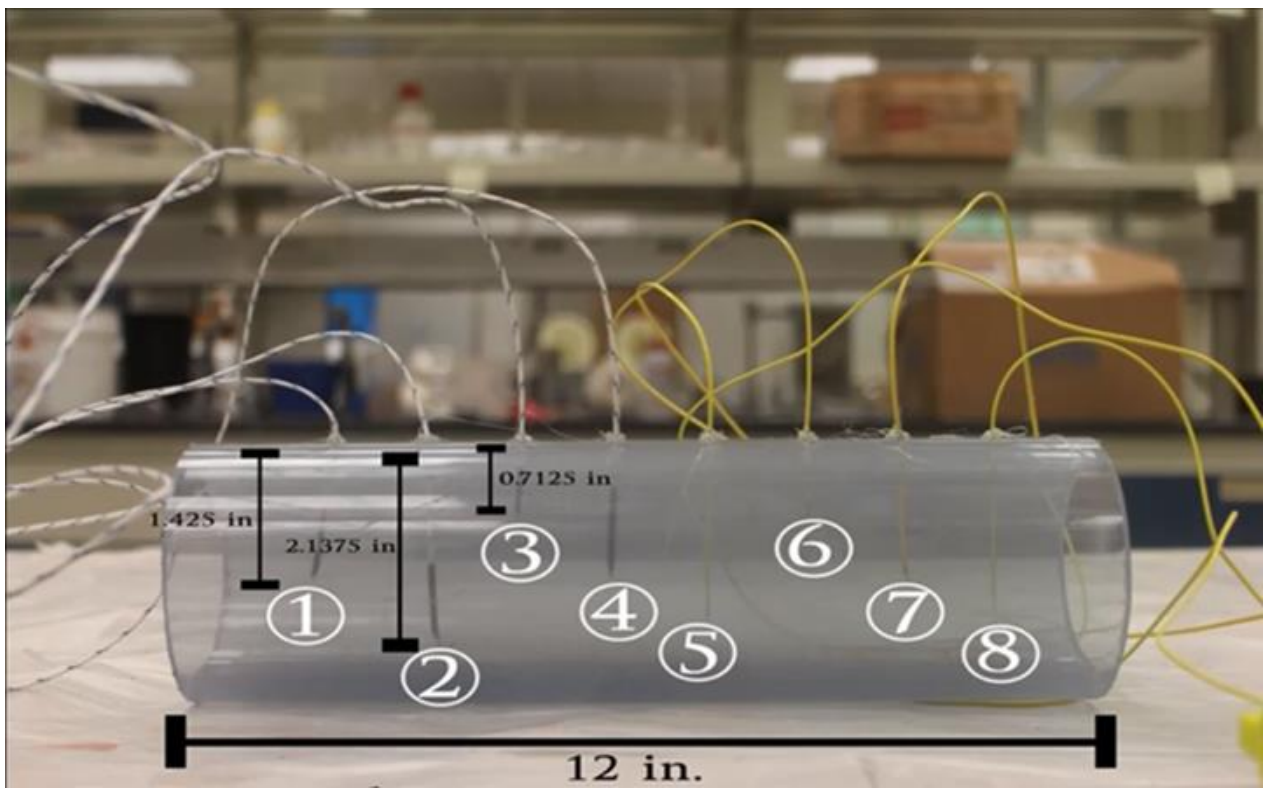

Figure 10. Clear PVC pipe with eight (8) thermocouples inserted along its length 


\subsection{Non-Destructive Evaluation (NDE) Method}

For the objective to investigate the viability of using curing temperature to give off heat signatures to detect inconsistencies and anomalies during the application and/or foam curing process. Since it is known that polyurethanes are made by the exothermic reactions between alcohols with two or more reactive hydroxyl groups per molecule (diols, triols, polyols) and isocyanates that have more than one reactive isocyanate group per molecule (Lazonby, 2015), the resulting heat generated during the polyurethane foam curing process can be detected through techniques using infrared cameras. The idea also came about from a similar experimental design that was also developed by researchers at SRNL, in which a thermal imaging camera was utilized to characterize the temperature profiles of foam samples within a set volume to ensure that excessive heat was nor generated during curing and that generated heat was dissipated at a reasonable rate (Nicholson, Peters, Wilson, \& Washington, 2016).

To determine the viability of the NDE Method, a series of experiments were designed using the down-selected COTS intumescent foam.

\subsubsection{NDE Step 1}

For the first part of this experimental design, the down-selected intumescent foam is poured into a 304-Stainless Steel pipe measuring four inches in diameter, with a wall thickness of 0.25 inches. The pipe was retrofitted with four internally placed Type K thermocouples that were inserted through four evenly spaced holes on the stainless-steel pipe exterior (figure below) to measure the curing temperature at different locations. Four additional thermocouples were also placed along the exterior of the stainless steel to 
measure the outer surface temperature, this was done to verify the readings from a thermal imaging camera (figure below).

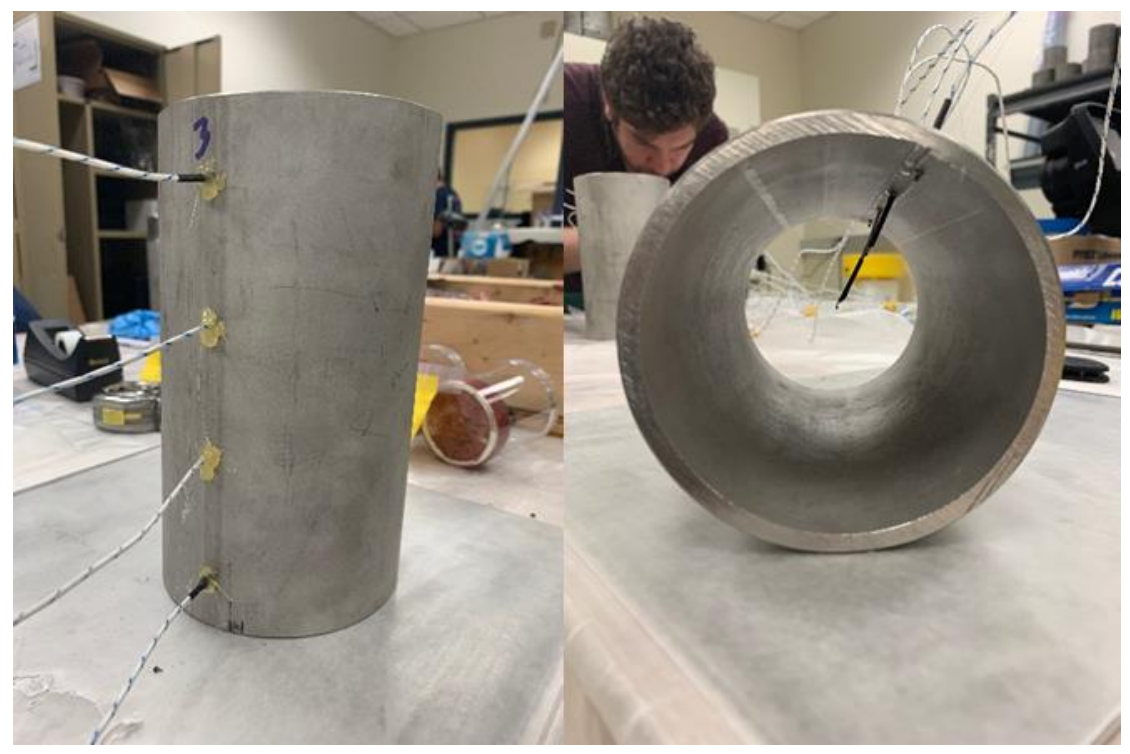

Figure 11. Internal Thermocouples (NDE Step 1)

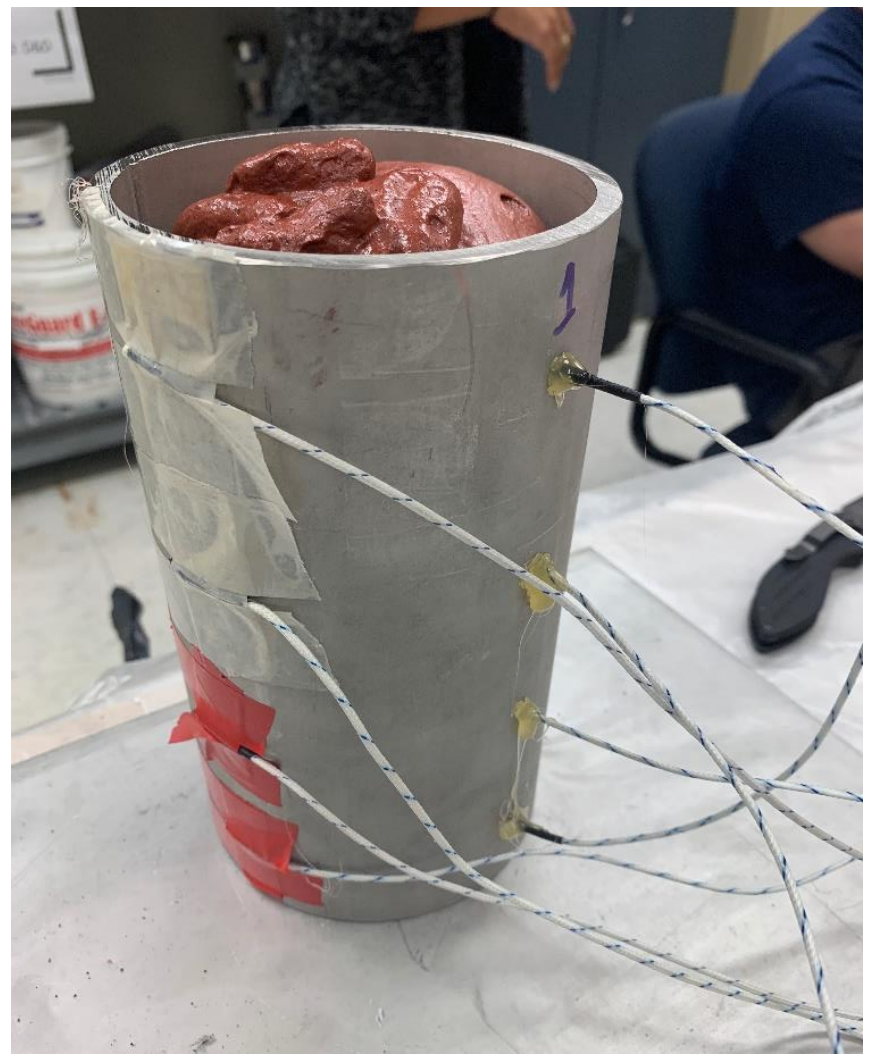

Figure 12. Externally Placed Thermocouples (NDE Step 1) 


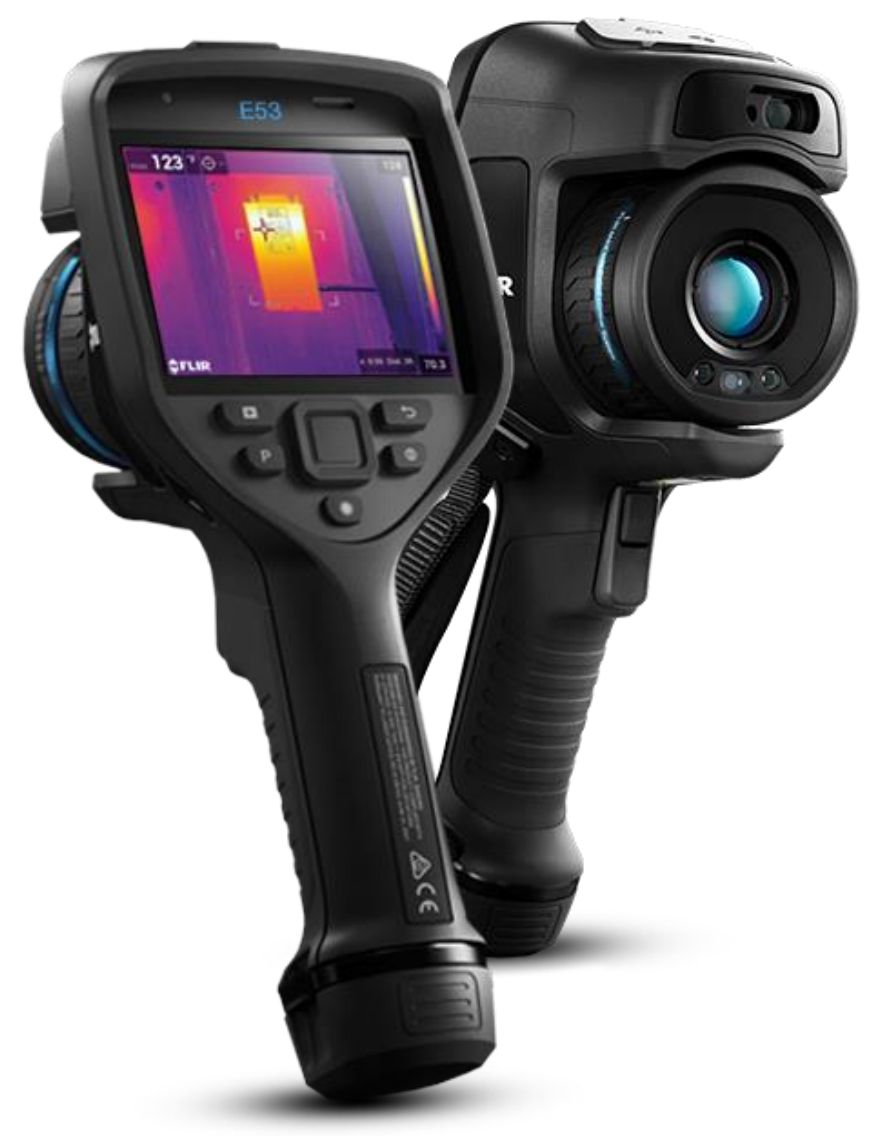

Figure 13. FLIR E53 Advanced Thermal Imaging Camera

\subsubsection{NDE Step 2}

For the second part of this experimental design, an obstruction was placed along the inner wall of a stainless steel pipe measuring 2 inches in diameter, with a wall thickness of 0.154 inches (figure below). The obstruction was carved out of Styrofoam to simulate an "inconsistency" during the application and/or foam curing process, or as an anomaly/artificiality within the pipe itself. The size of the Styrofoam cutout measures approximately 2-inch by 2-inch. The FLIR E53 thermal imaging camera will be used to capture still images for analysis. 


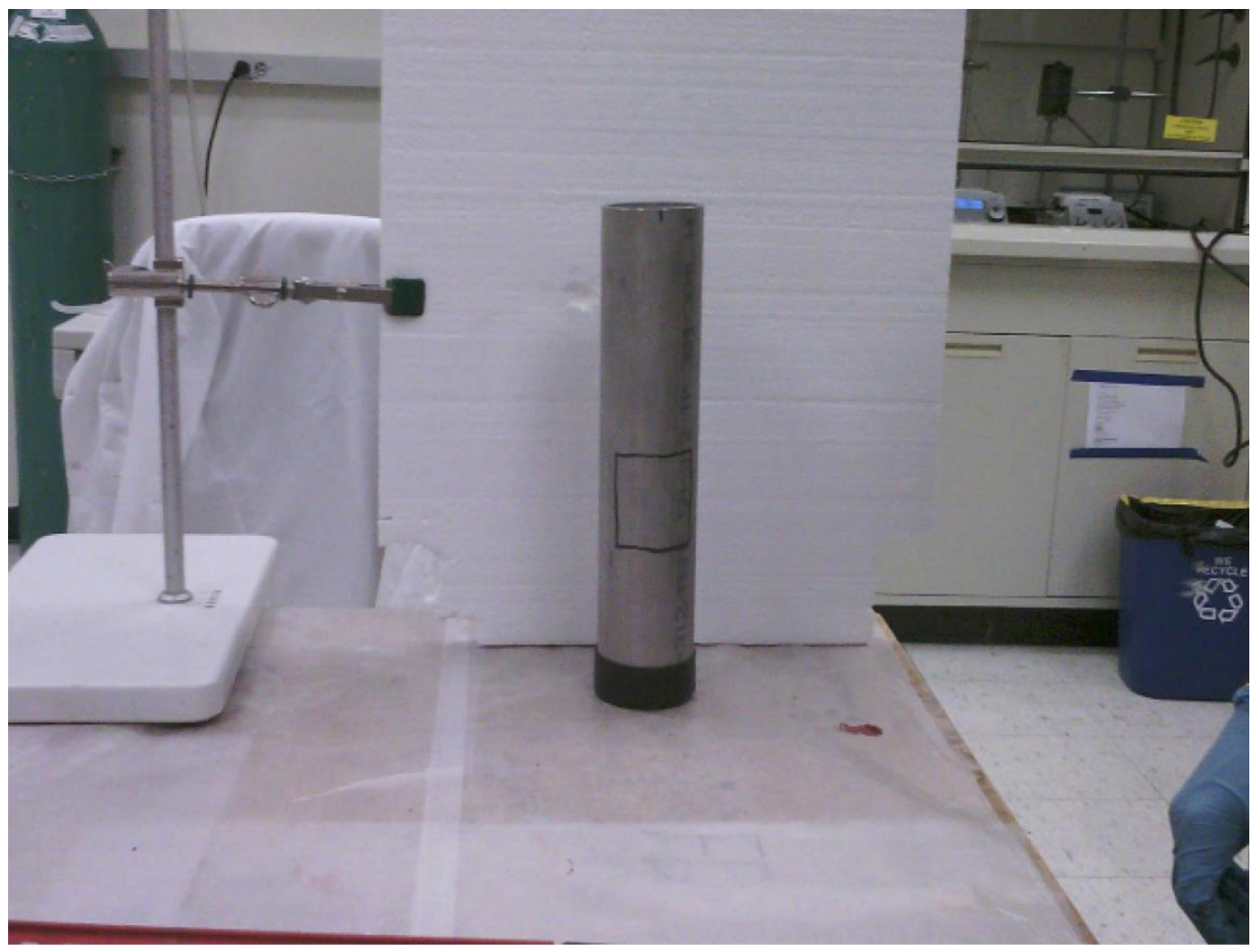

Figure 14. Step 2 NDE Pipe

Alongside visual analysis of the captured still thermal images, the FLIR hardware will be supplemented by FLIR Tools Thermal Analysis and Reporting Software which allows you to thermally tune level and span, change color palette, or adjust parameters such as emissivity, and reflective temperature. 


\section{CHAPTER IV - RESULTS AND DISCUSSION}

\subsection{Baselining of Existing Polyurethane Foams}

The main focus in this sections work is to investigate the applicability of a near-fit standard to be able to test and evaluate polyurethane foams to thermal stressors in accordance the IEC 60695-11-10 flammability classification, along with a 2-hour long exposure to direct flame test, and a mass loss test by subjecting the foam samples to incremental temperature increases inside a muffle furnace in order to complement FIU's role to more closely align with the safety and fire basis requirements of the SRS 235-F facility.

\subsubsection{The Flammability Classification}

For the analysis and down-selection process, the potential foam samples were separated and grouped into their respective fire rating categories; non-fire rated, fire-rated, and intumescent. Also, with their flammability classification under IEC 60695-11-10, four performance metrics were established that each sample was evaluated for; meeting fire safety requirements, their ability to maintain structural integrity, thermal insulation, and whether flame and/or smoke propagation occurred. 


\begin{tabular}{|c|c|c|c|}
\hline \multicolumn{4}{|c|}{ IEC 60695-11-10 - Vertical Test } \\
\hline \multicolumn{2}{|c|}{ Date of Test: } & \multicolumn{2}{|c|}{ 19-Dec } \\
\hline \multirow{3}{*}{ FlexFoam iT 14} & \multicolumn{2}{|c|}{ Afterflame Time (min:sec) } & Sample Length (in) \\
\hline & Trial \#1 & 7:04 & 1.904 \\
\hline & Trial \#2 & & \\
\hline \multirow{3}{*}{ FlexFoam iT 23 FR } & \multicolumn{2}{|c|}{ Afterflame Time (min:sec) } & Sample Length (in) \\
\hline & Trial \#1 & $0: 01$ & 1.471 \\
\hline & Trial \#2 & $0: 01$ & \\
\hline \multirow{3}{*}{ FlexFoam iT 7 FR } & \multicolumn{2}{|c|}{ Afterflame Time (min:sec) } & Sample Length (in) \\
\hline & Trial \#1 & $0: 00$ & 3.754 \\
\hline & Trial \#2 & $0: 00$ & \\
\hline \multirow{3}{*}{ Foam iT 8} & \multicolumn{2}{|c|}{ Afterflame Time (min:sec) } & Sample Length (in) \\
\hline & Trial \#1 & $1: 23$ & 3.242 \\
\hline & Trial \#2 & $0: 00$ & \\
\hline \multirow{3}{*}{ 3M Fire Barrier FR } & \multicolumn{2}{|c|}{ Afterflame Time (min:sec) } & Sample Length (in) \\
\hline & Trial \#1 & $0: 00$ & 2.688 \\
\hline & Trial \#2 & $0: 00$ & \\
\hline \multirow{3}{*}{ Hilti FR } & \multicolumn{2}{|c|}{ Afterflame Time (min:sec) } & Sample Length (in) \\
\hline & Trial \#1 & $0: 00$ & 3.277 \\
\hline & Trial \#2 & $0: 00$ & \\
\hline \multicolumn{4}{|c|}{ Notes } \\
\hline \multicolumn{4}{|c|}{ Sample was secured 12 inches above cotton. } \\
\hline \multicolumn{4}{|c|}{ Flame was applied to each sample for 10 seconds. } \\
\hline \multicolumn{4}{|c|}{ Cotton was observed for fires caused by falling particles. } \\
\hline
\end{tabular}

Table 1. IEC 60695-11-10 - Vertical Test Results

For the vertical test, since IEC 60695-11-10 is used here as a "near-fit" testing standard, a maximum of only two trials were needed to determine whether or not the foam samples were able to withstand a direct flame exposure. The times recorded indicate how long it took for the foam samples to self-extinguish after the flame application. The FlexFoam iT 4 and iT 8 samples only underwent a single trial, as the first trials failed to self-extinguish, a second trial was not necessary. 


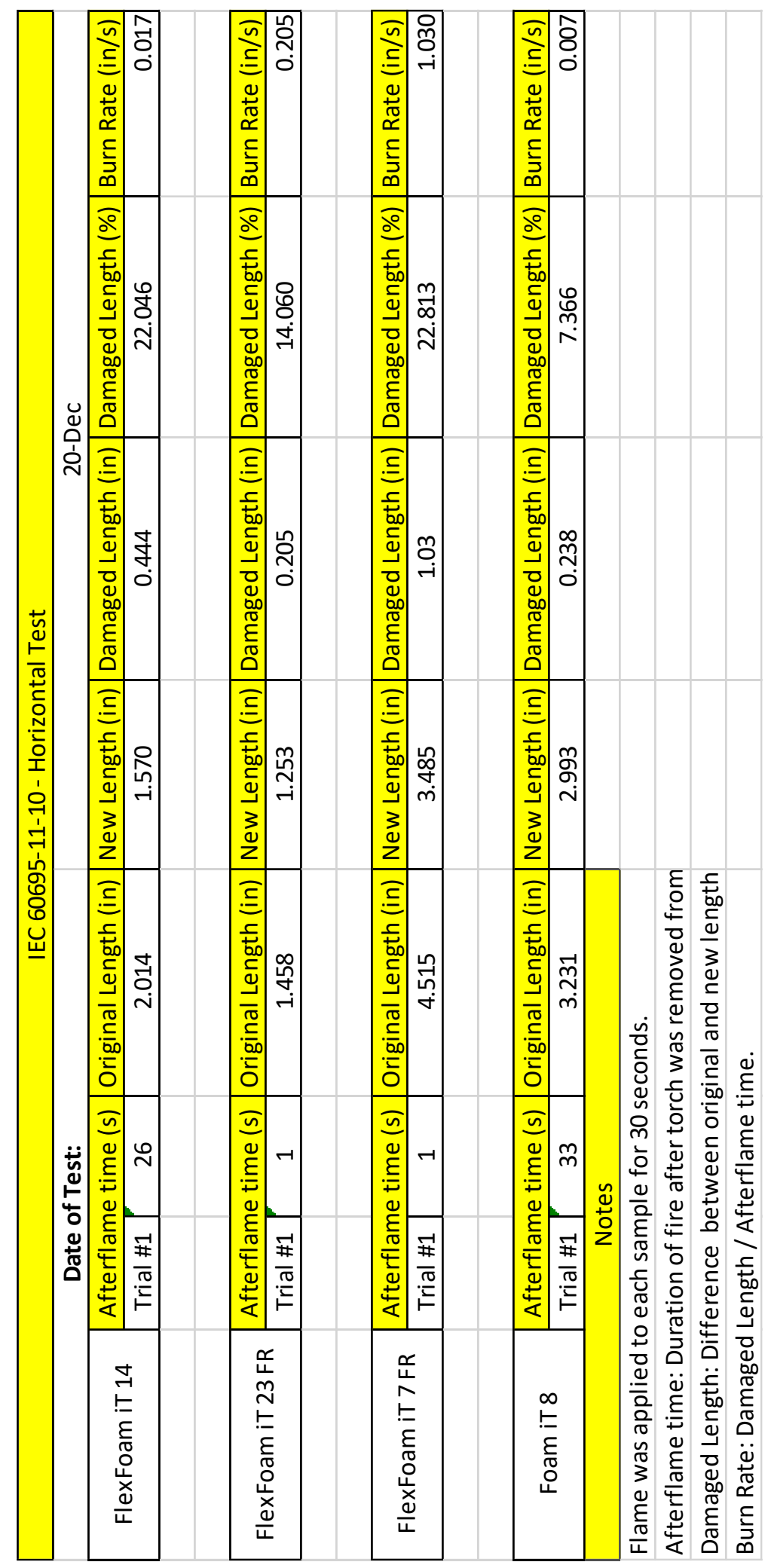

Table 2. IEC 60695-11-10 - Horizontal Test Results; after one trial 
The non-fire rated and fire-rated foam samples (figures below) both failed to meet safety requirements, had a major loss in structural integrity, displayed poor thermal insulation, and exhibited both flame and smoke propagation. Along with performing poorly during the flammability characterization, and in terms of fire resiliency, all the nonintumescent (non-fire rated, and fire rated) foam samples failed to withstand even 15 minutes of exposure to a direct flame (from a propane torch).

- Duration:

Duration:

14 min \& 45 seconds

- Flame and smoke propagation:

- Structural integrity:

- Thermal insulation:

- Flame and smoke propagation:

- Structural integrity:

- Thermal insulation:
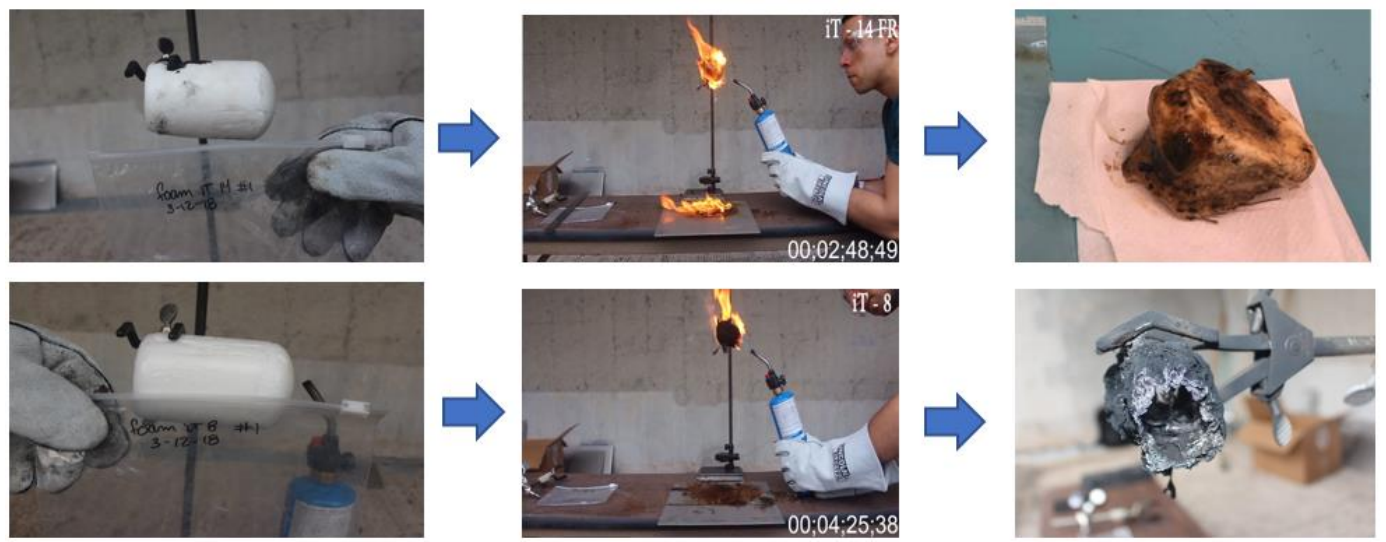

Figure 15. Testing of Non-Fire Rated Foam Samples 
- Flame and smoke propagation:

- Structural Integrity:

- Thermal Insulation:

- Duration:

- Flame and smoke propagation:

- Structural Integrity:

- Thermal Insulation:
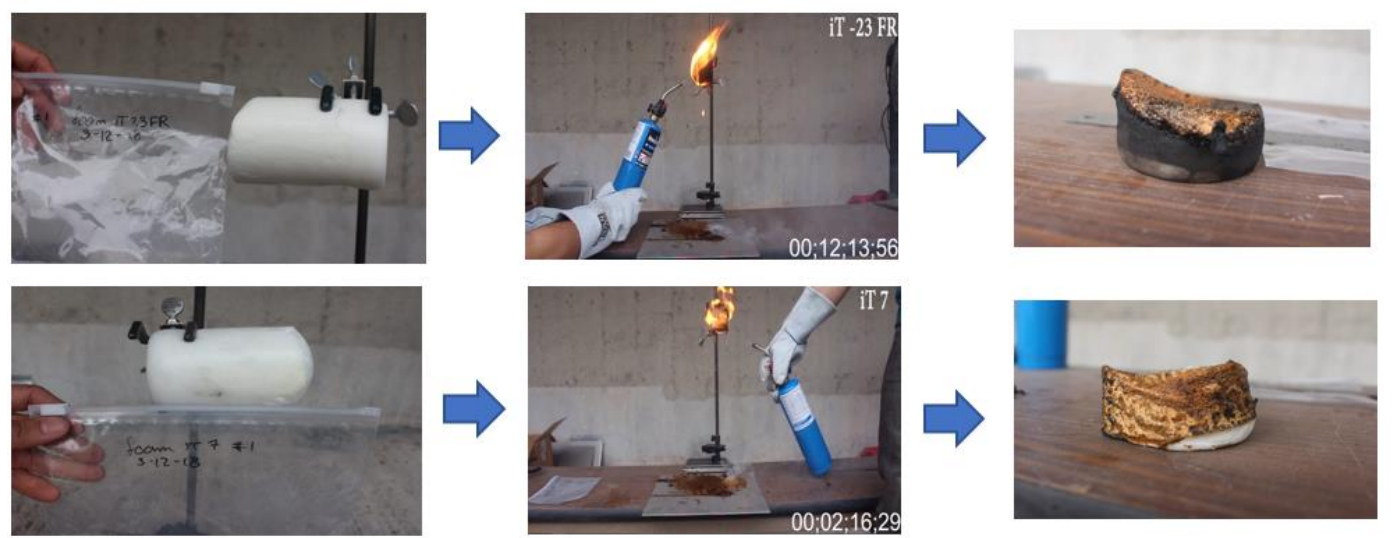

Figure 16. Testing of Fire Rated Foam Samples

The intumescent foam samples (Figure 17) on the other hand, performed excellently and were found to best-in-class in each performance metric. They met fire safety requirements, and in many cases exceeded them, maintained their structural integrity, displayed excellent thermal insulation, and exhibited little to no flame or smoke propagation. 
- Flame and smoke propagation:

- Structural integrity:

- Thermal insulation:
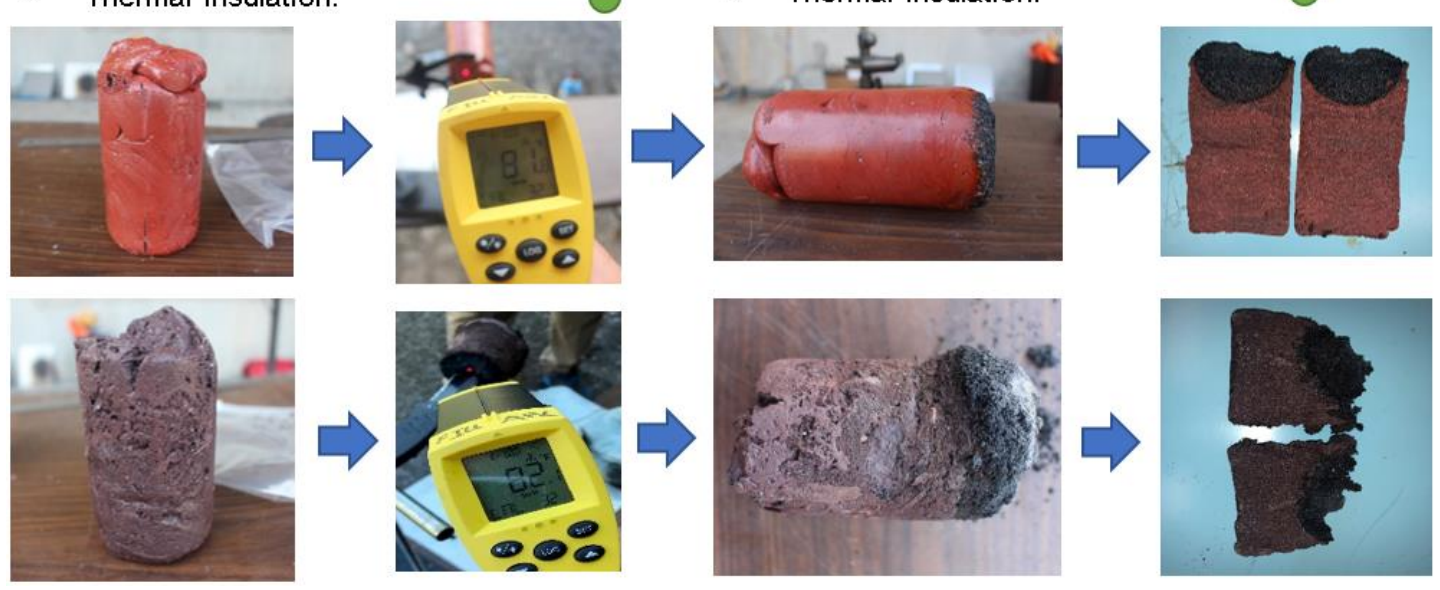

Figure 17.Testing of Intumescent Foam Samples

\subsubsection{2-Hour Direct Flame Exposure}

Along with performing poorly during the flammability characterization, and in terms of fire resiliency, all the non-intumescent (non-fire rated, and fire-rated) foam samples failed to withstand even 15 minutes of exposure to a direct flame (from a propane torch). The intumescent foam samples far exceeded the other foam samples in terms of fire resiliency, and the subsequent series of testing. During the direct flame testing, zero flame or smoke propagation was noted, and significant thermal insulation capabilities were demonstrated, with temperatures above $1400^{\circ} \mathrm{F}$ on the exposed end but never surpassing $84^{\circ} \mathrm{F}$ on the back end during the 2-hour flame exposure period. This material exhibited only marginal structural degradation after two full hours of a direct flame from a propane torch. There was no registered loss in diameter and only $4 \mathrm{~mm}$ of shrinkage in length. When dissected, the structural integrity of the first intumescent foam sample (Hilti) was solid and 
relatively intact. The second intumescent foam sample (3M) also performed well, with no flame or smoke propagation and significant thermal insulation. While this particular sample also maintained the structural integrity of the non-damaged portion, there was a significant loss of the length, diameter, and mass.
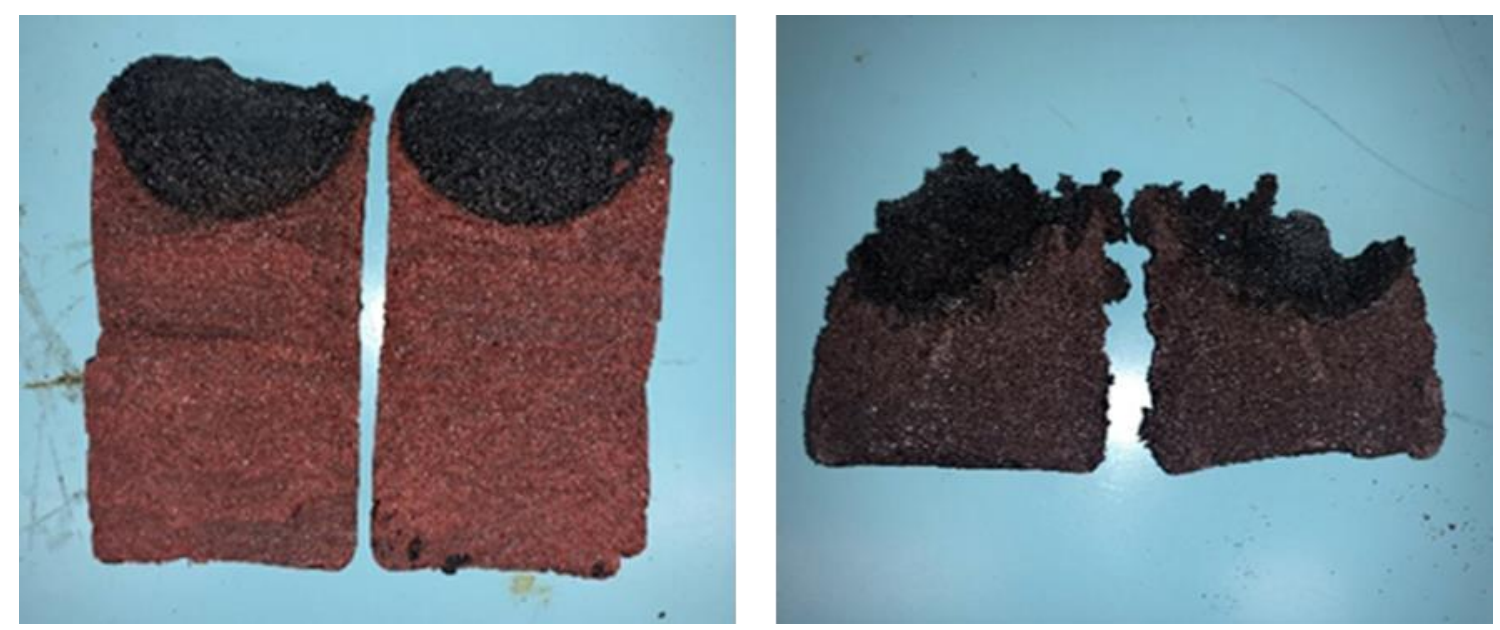

Figure 18. Dissected Intumescent Foam Samples; Hilti(left) and 3M(right)

\subsubsection{Incremental Temperature Experiment}

The results of this experiment were generally consistent with the previous series of tests, with the non-fire rated foam samples losing the most mass, the fire-rated samples following afterward, and the intumescent foams samples losing the least amount of mass. 


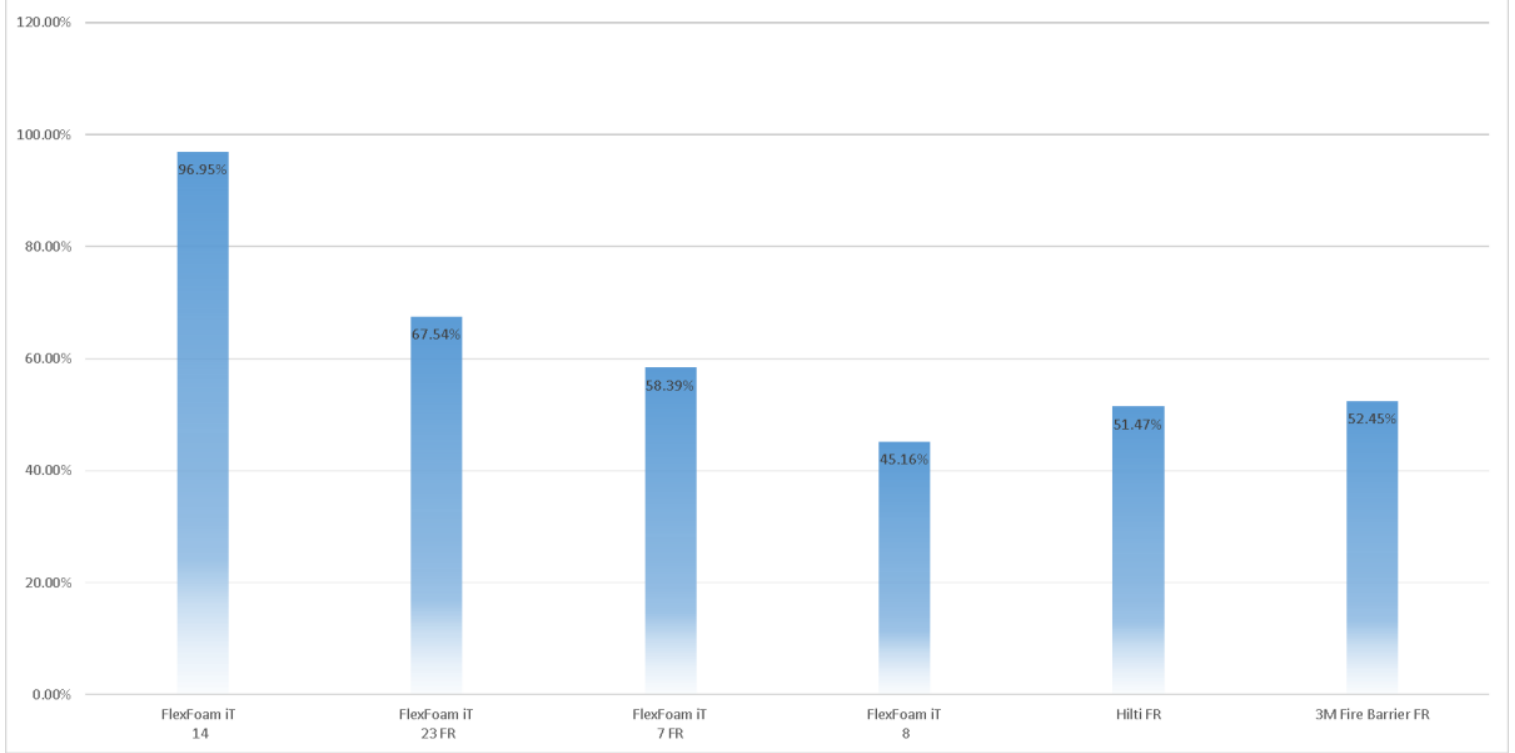

Figure 19. Total Mass Loss of Foam Samples; done only once

Of the two non-fire rated samples the mass loss varied significantly, however, the remaining samples (fire-rated and intumescent) which possess fire resistive qualities, tended to lose less mass when subjected to the same thermal stress. Mass loss under thermal stress is an important behavior to be aware of, but is not necessarily a good indicator of overall performance. Given the limitations of replicate samples, it is difficult to draw a generalized performance metric for mass loss due to thermal stress.

\begin{tabular}{|l|r|}
\hline \multicolumn{2}{|c|}{ Median Mass Loss } \\
\hline Non- Fire Rated & $71.1 \%$ \\
\hline Fire Rated & $63 \%$ \\
\hline Intumescent & $52 \%$ \\
\hline
\end{tabular}

Table 3. Median Mass Loss of Foam Samples 


\subsection{Curing Temperature Profile Experiment}

Initial data points of replicate samples recorded changes in temperature every two seconds until a negative gradient started to develop. The temperature range was from 255.6 ${ }^{\circ} \mathrm{F}$ to $261.1^{\circ} \mathrm{F}$.

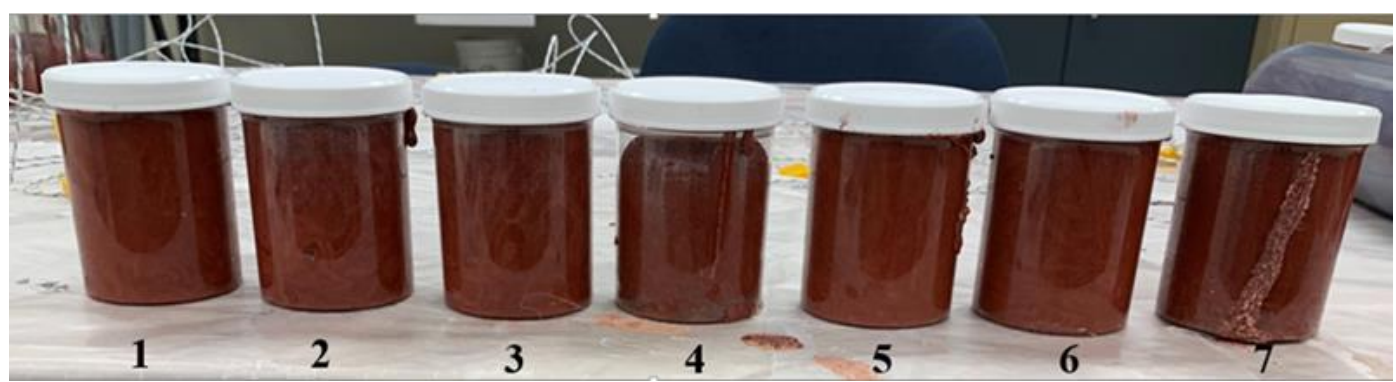

Figure 20. Polystyrene Containers Filled with Replicate Hilti Intumescent Foam Samples

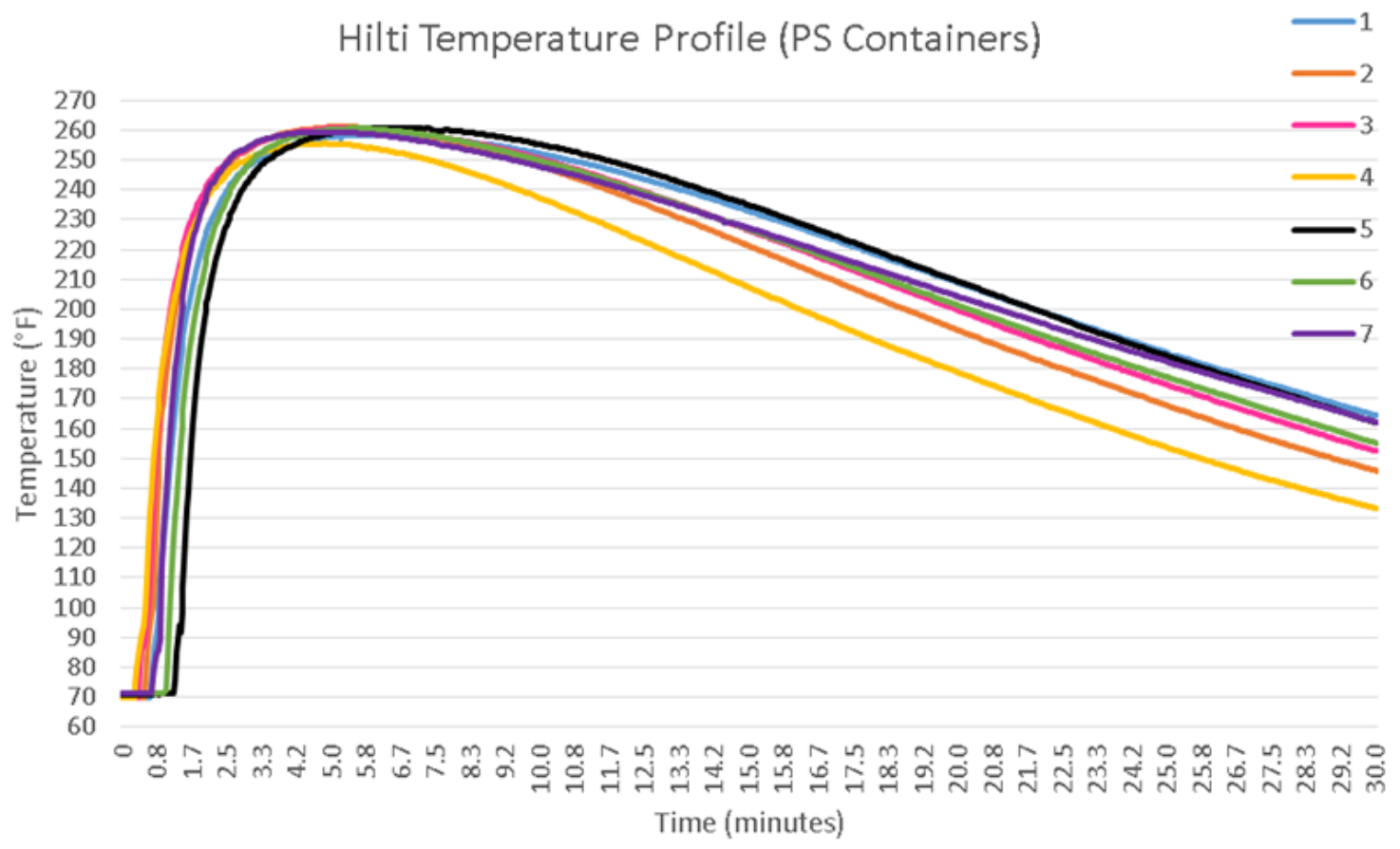

Figure 21. Curing Temperature Profile of Hilti Intumescent Foam; each numbered line in the legend refers to the associated thermocouple used in the curing temperature profile experiment. 


\subsection{Uniformity of Curing/Initial Proof-of-Concept}

The data collected from the analysis shows a clear distinction between fully, partially, and non-encapsulated thermocouples within the intumescent foam tube (figure below). The results of the initial proof-of-concept experiment confirm the hypothesis and establish that there is a distinct correlation between the temperature profile during the foam curing process, and the artificialities created during the application of the within the clear PVC pipe.

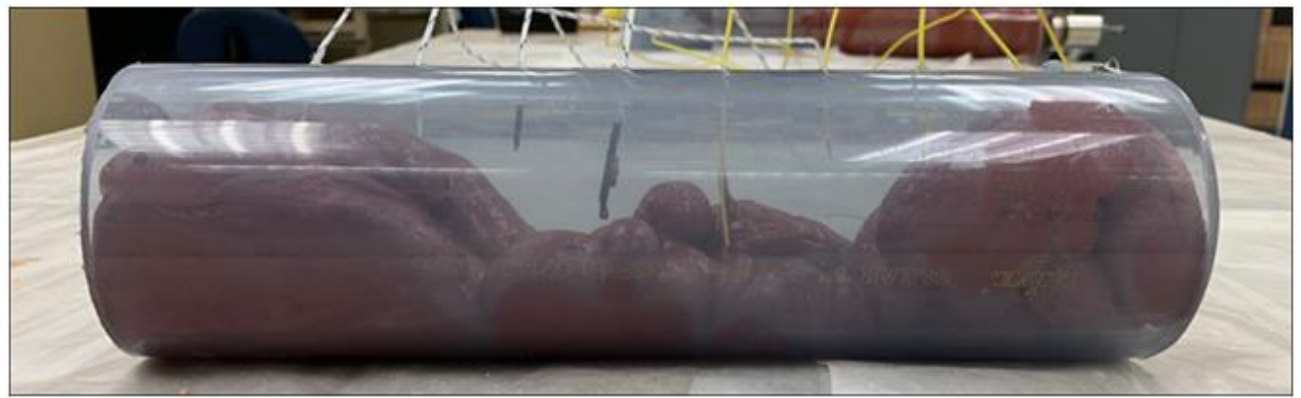

Figure 22. Initial Proof-of-Concept Result

\begin{tabular}{|c|c|}
\hline \multicolumn{2}{|c|}{ Fully Encapsulated } \\
\hline 1 & 263.8 \\
\hline 8 & 270.5 \\
\hline \multicolumn{2}{|c|}{ Partially Encapsulated } \\
\hline THERMOCOUPLE & MAX TEMPERATURE ( $\left.{ }^{\circ} \mathrm{F}\right)$ \\
\hline 2 & 232.1 \\
\hline 5 & 217.8 \\
\hline 7 & 240.8 \\
\hline \multicolumn{2}{|c|}{ Not Encapsulated } \\
\hline THERMOCOUPLE & MAX TEMPERATURE ( $\left.{ }^{\circ} \mathrm{F}\right)$ \\
\hline 3 & 120.5 \\
\hline 4 & 146.6 \\
\hline 6 & 131.7 \\
\hline
\end{tabular}

Table 4. Thermocouple Data 


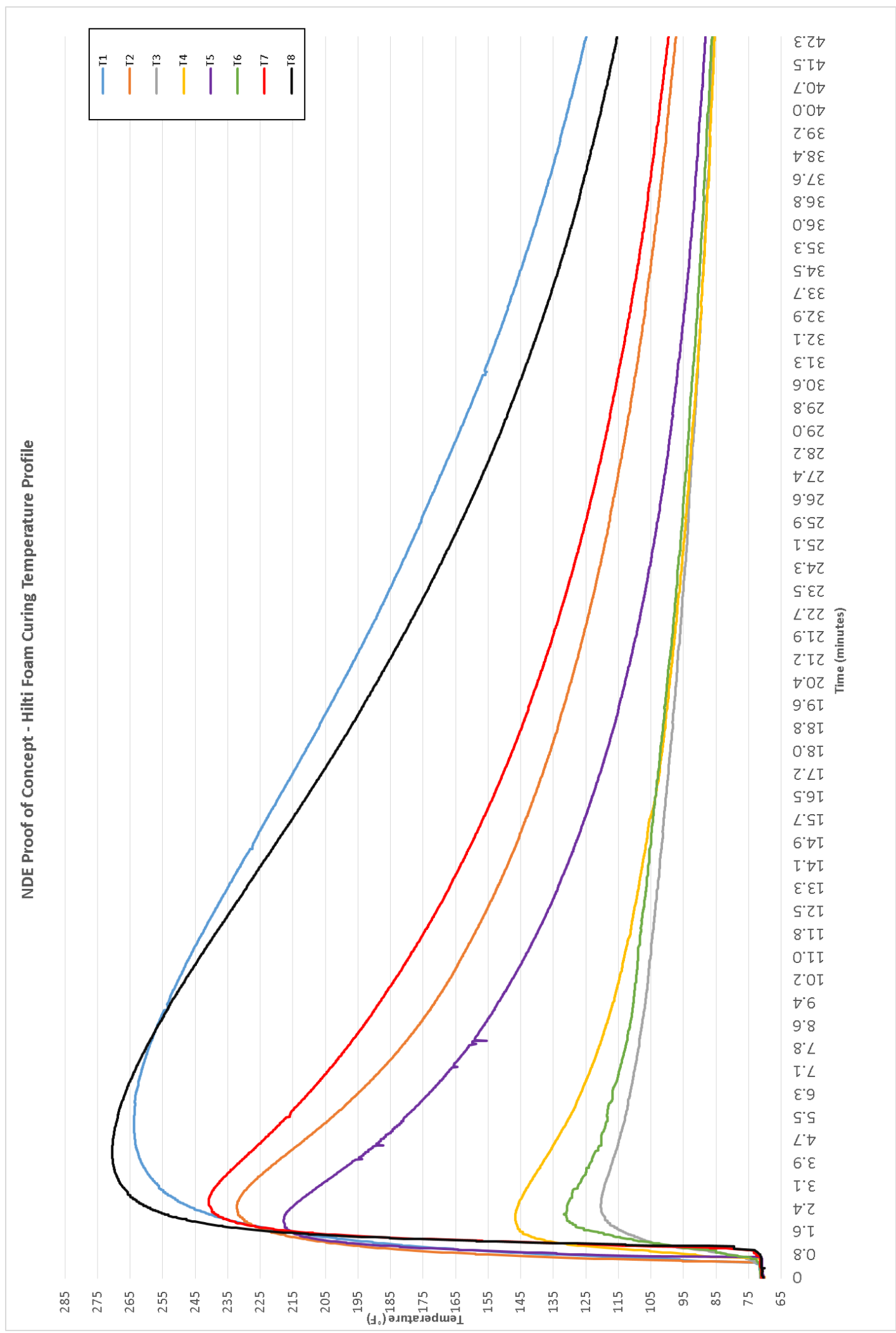

Figure 23. Thermocouple Temperature Curves; each numbered line in the legend refers to the associated thermocouples used in the initial proof-of-concept 


\subsection{Non-Destructive Evaluation (NDE) Method}

\subsubsection{NDE Step 1}

The experimental data was able to visually verify a uniformly cured application of the intumescent foam within the 304-stainless steel pipe, as the temperature readings were recorded with a $0.24 \%$ accuracy of each other. The video and still image thermography captured on the thermal imaging camera was processed by the FLIR Tools Thermal Analysis and Reporting software.

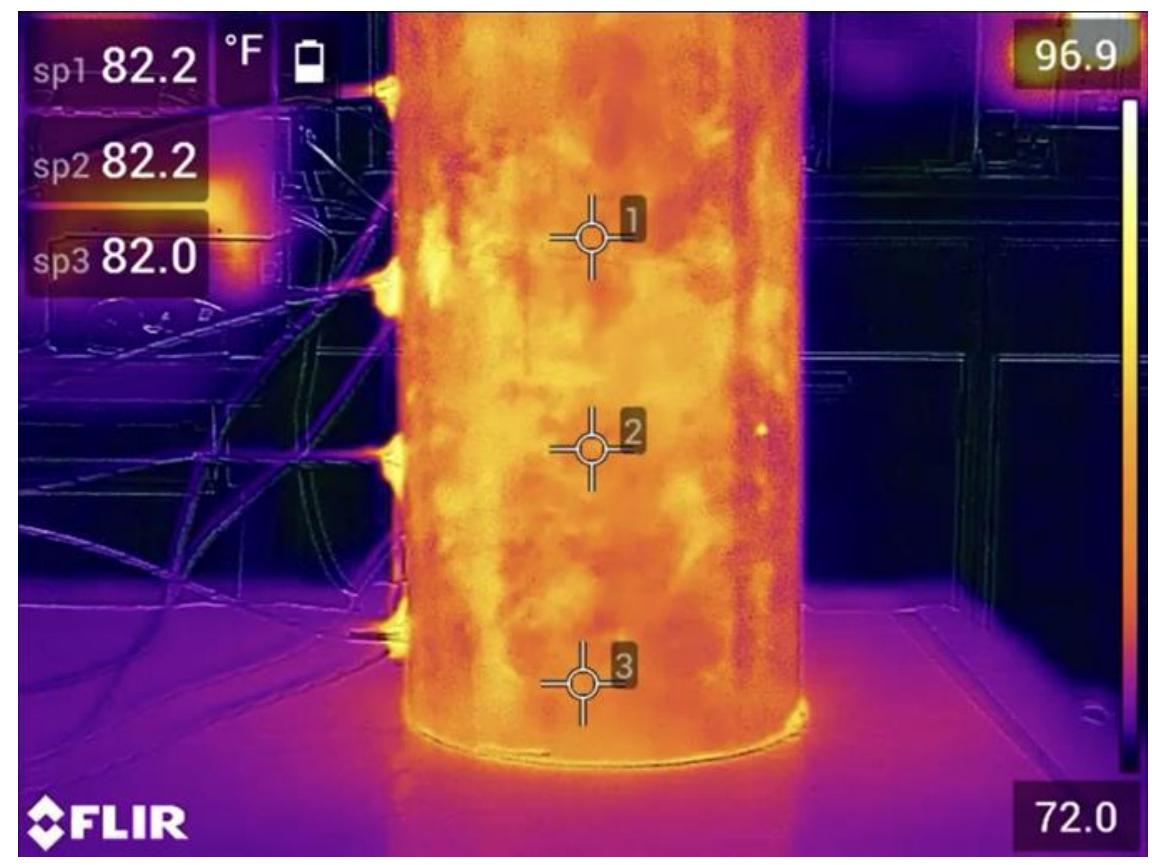

Figure 24. Step 1 NDE Snapshot from FLIR Thermal Imaging Camera

\subsubsection{NDE Step 2}

The results of this experiment show a clear cold spot from a purposely placed obstruction within the 304-stainless steel pipe. The obstruction was not able to be visually verified by the thermal images, but also through numerical analysis by utilizing the FLIR 
Tools software. After the images are processed, the software many measurements in postproduction (Figure 25).

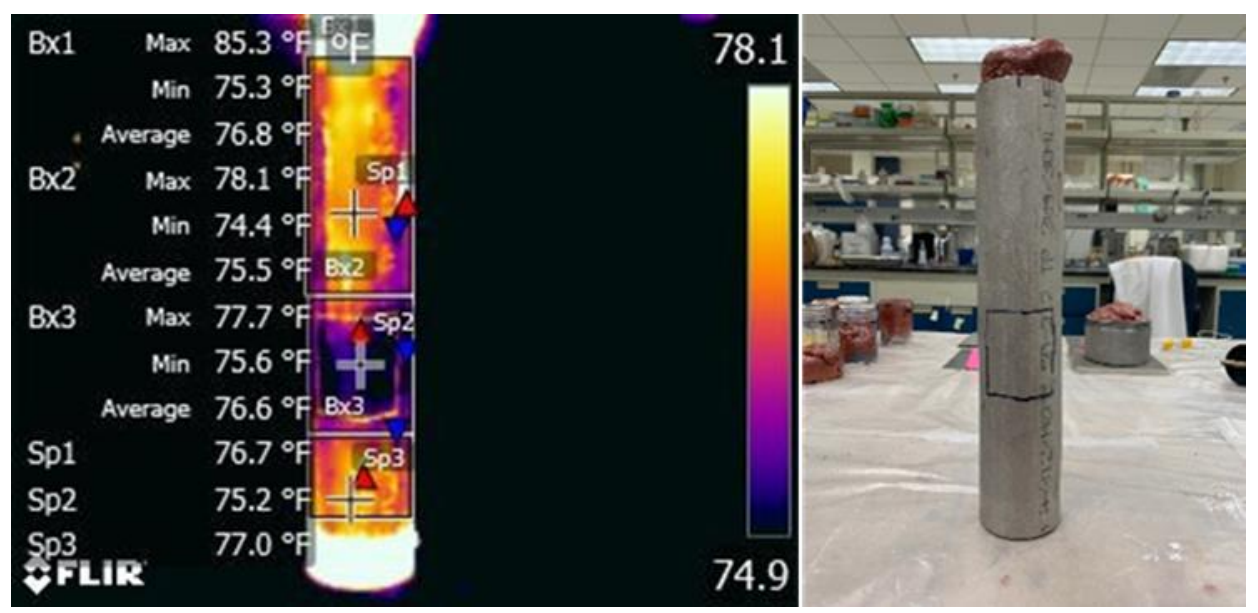

Figure 25. Side-by-side Comparison of Thermal Image and Normal Image

The results of this experiment were not only gathered through visual analysis of the thermal images but also by implementing "measurement boxes" within the FLIR software. Along with being able to measure the maximum, minimum, and average temperatures in each measurement box, it can also other parameters such as emissivity, reflective temperature, distance, and relative humidity. To collect only the relevant data of the pipe itself, the contrast was refocused around just the pipe itself to create a greater and more apparent temperature gradient between the different temperature variations (figure below).

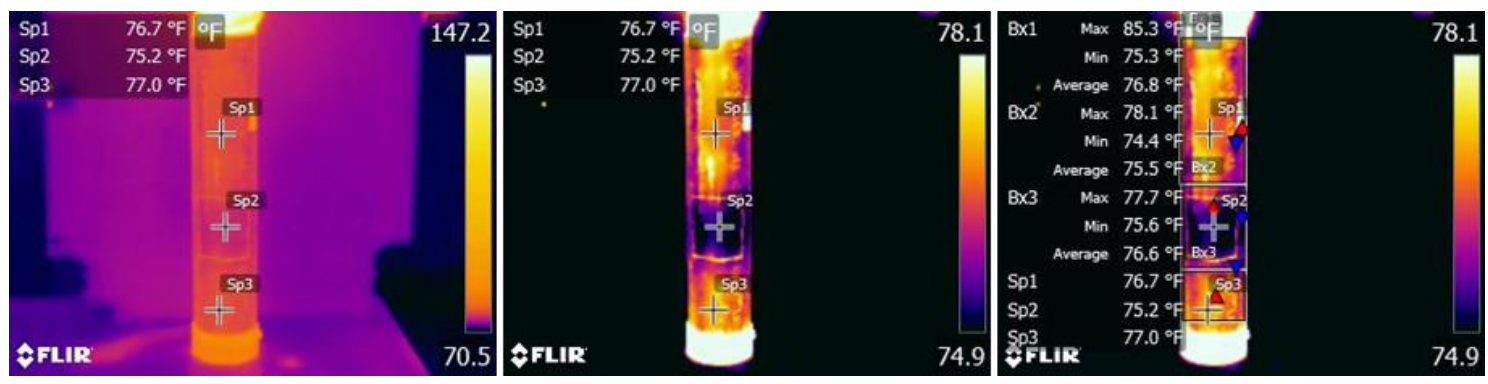

Figure 26. Thermal image Undergoing Visual Analysis with FLIR Software 


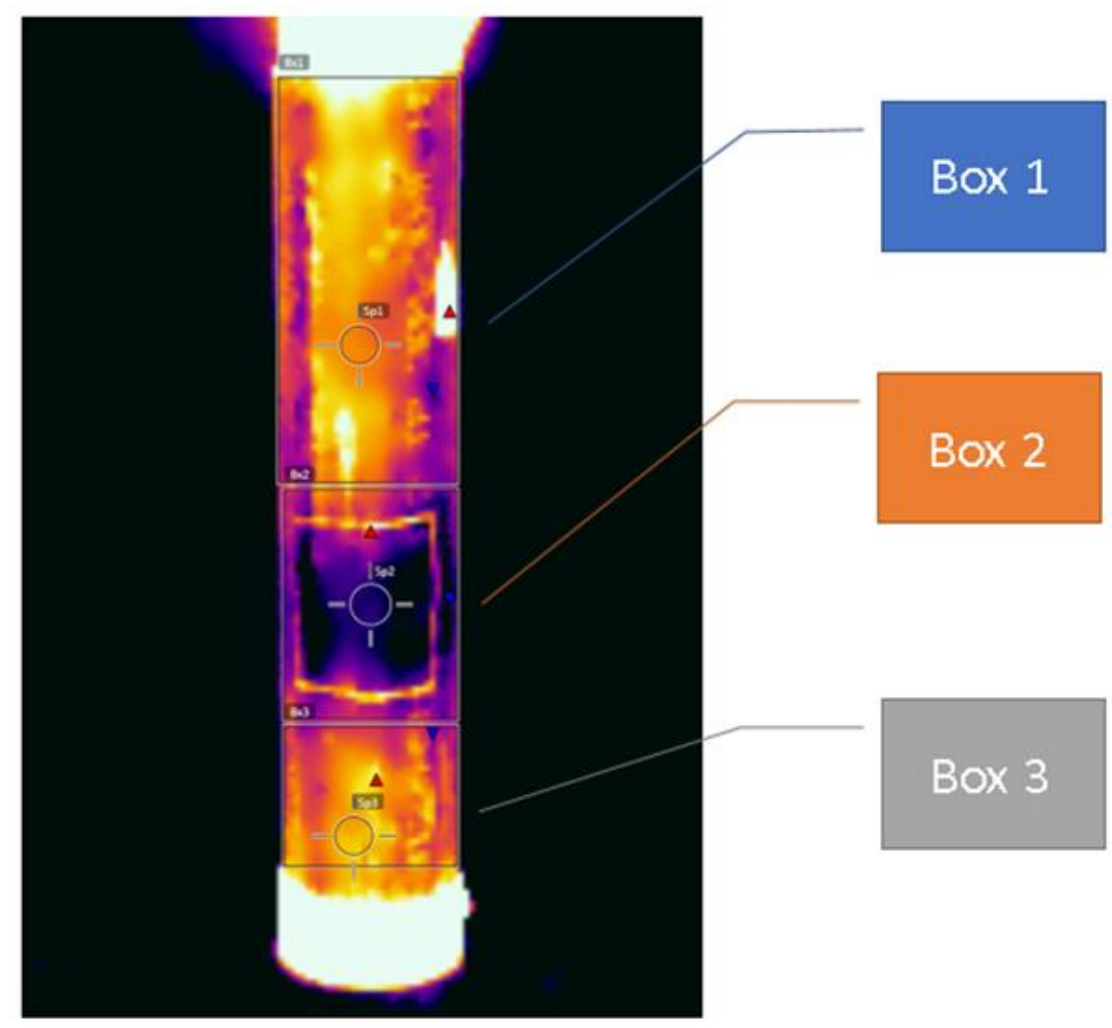

Figure 27. Measurements boxes in FLIR software for gathering numerical data

The measurement boxes were labeled, and the data was extracted and imported into an Excel worksheet. Only the average temperatures of each box were used for numerical analysis (Table 5). 


\begin{tabular}{|c|c|c|c|c|c|}
\hline \multicolumn{6}{|c|}{ Average Temperatures } \\
\hline & Time Stamp & Time (seconds) & Box 1 & Box 2 & Box 3 \\
\hline 1 & 10:42:10 & 00 & 76.4 & 75.5 & 76.4 \\
\hline 2 & 10:42:45 & 35 & 76.8 & 75.5 & 76.6 \\
\hline 3 & $10: 43: 13$ & 63 & 77.6 & 76.2 & 77.2 \\
\hline 4 & 10:43:45 & 95 & 78.3 & 76.9 & 77.8 \\
\hline 5 & 10:44:16 & 126 & 78.7 & 77.3 & 78 \\
\hline 6 & 10:44:46 & 156 & 78.8 & 77.5 & 78 \\
\hline 7 & 10:45:15 & 185 & 79.3 & 78 & 78.4 \\
\hline 8 & $10: 45: 47$ & 217 & 80 & 78.6 & 78.8 \\
\hline 9 & 10:46:17 & 247 & 79.9 & 78.7 & 78.9 \\
\hline 10 & 10:46:48 & 278 & 80 & 78.8 & 78.9 \\
\hline 11 & $10: 47: 18$ & 308 & 80.2 & 79.1 & 79 \\
\hline 12 & $10: 47: 50$ & 340 & 80.2 & 79.1 & 79 \\
\hline 13 & $10: 48: 20$ & 370 & 80.6 & 79.6 & 79.3 \\
\hline 14 & $10: 48: 51$ & 401 & 81 & 79.8 & 79.4 \\
\hline 15 & 10:49:21 & 431 & 80.6 & 79.7 & 79.3 \\
\hline 16 & 10:49:52 & 462 & 80.5 & 79.7 & 79.1 \\
\hline 17 & $10: 50: 22$ & 492 & 80.5 & 79.7 & 79.1 \\
\hline 18 & 10:50:54 & 524 & 81.1 & 80.1 & 79.5 \\
\hline 19 & 10:51:24 & 554 & 81.1 & 80.2 & 79.5 \\
\hline 20 & 10:51:55 & 585 & 80.9 & 80.1 & 79.3 \\
\hline 21 & 10:52:25 & 615 & 80.8 & 79.9 & 79.2 \\
\hline 22 & 10:52:57 & 647 & 81.2 & 80.4 & 79.6 \\
\hline 23 & 10:53:26 & 676 & 81.1 & 80.1 & 79.3 \\
\hline 24 & $10: 53: 57$ & 707 & 80.8 & 80 & 79 \\
\hline 25 & 10:54:28 & 738 & 81.3 & 80.5 & 79.5 \\
\hline 26 & 10:55:05 & 775 & 81.3 & 80.4 & 79.4 \\
\hline 27 & $10: 55: 34$ & 804 & 81 & 80.1 & 79.1 \\
\hline 28 & $10: 56: 06$ & 836 & 81.2 & 80.3 & 79.3 \\
\hline 29 & 10:56:34 & 864 & 81.1 & 80.3 & 79.2 \\
\hline 30 & 10:57:09 & 899 & 80.9 & 80.1 & 79 \\
\hline 31 & $10: 57: 39$ & 929 & 81 & 80.1 & 79.1 \\
\hline
\end{tabular}

Table 5. Average Temperatures from Thermal Images

The results were then plotted and represented as temperature versus time graph (Figure 28). 


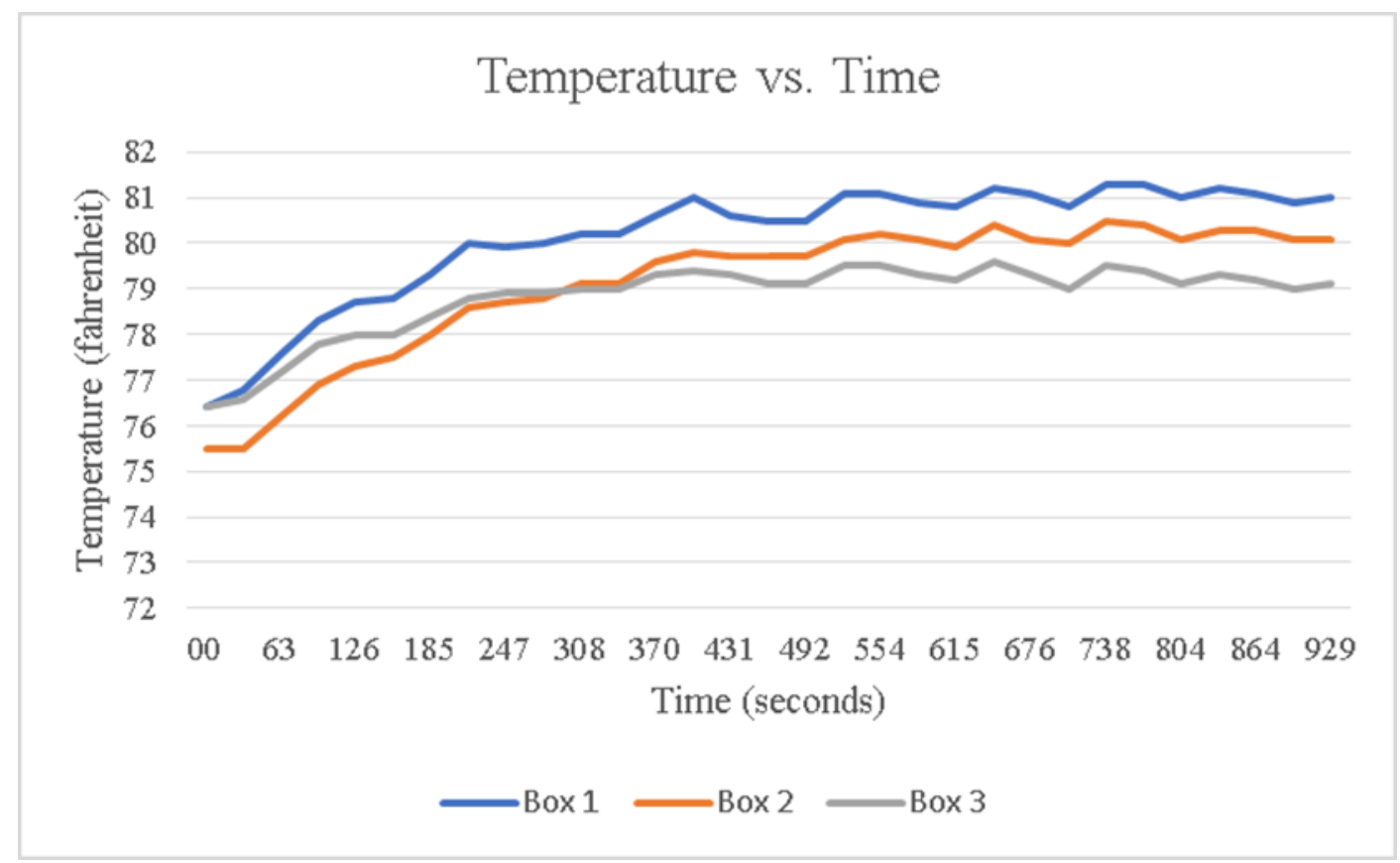

Figure 28. Temperature vs. Time Plot of Measurement Boxes

As the temperature began to normalize and reach equilibrium, the average temperature gap around the obstruction with regards to the rest of the pipe started to become narrow and taper off. After the 3-minute and 37-second mark (figure below), the average temperature of "box 2" reaches about the same relative average temperatures as "Box1" and "Box 3." The time before "box 2" reaches this point, is referred to as the "Window of Opportunity" in regards to being able to detect anomaly/artificiality within the foam.

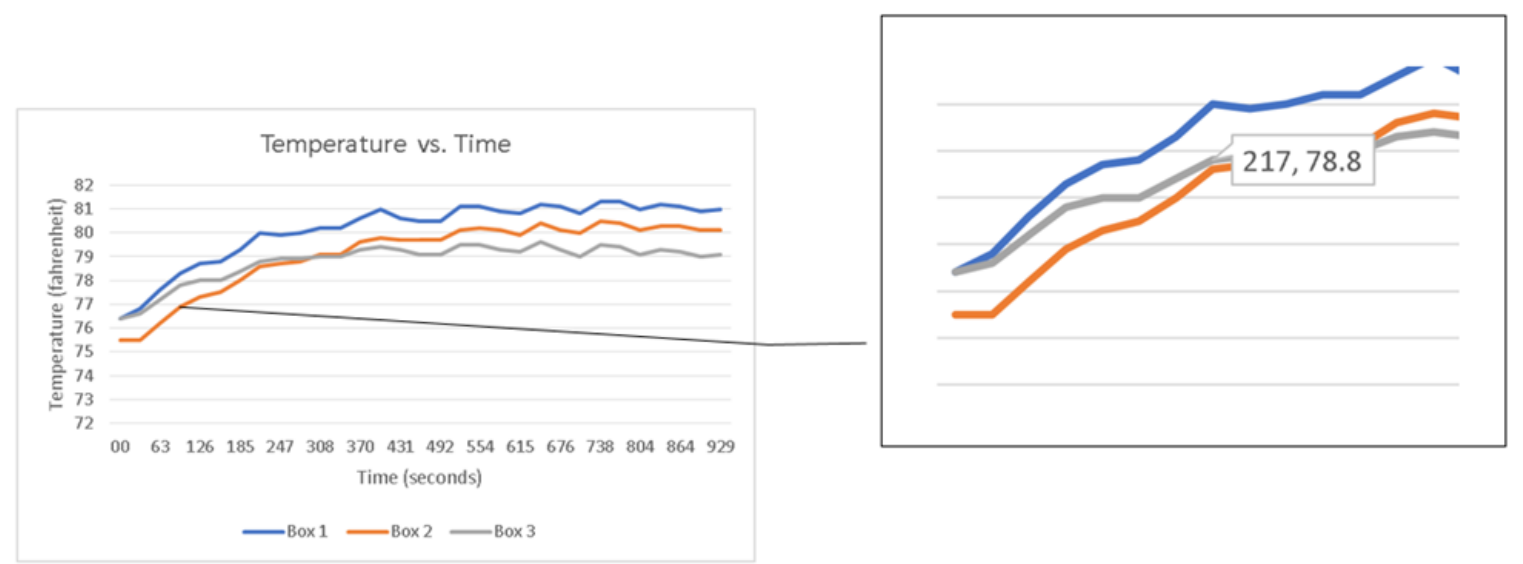

Figure 29. "Window of Opportunity" Captured at 03:37 


\section{CHAPTER V - CONCLUSION AND FUTURE WORK}

The results from the NDE experiments provide evidence that to support the hypothesis that there is a correlation between the temperature curing profile of intumescent foam during the curing process and inconsistencies in the application and/or curing. The results also showed that it is possible to detect anomalies and artificialities within the foam during the curing process, which would most definitely lead to a better more successful implementation of intumescent foam in areas where it would otherwise be much more difficult to assess. More specifically, areas of applications in regards to the deactivation \& decommissioning (D\&D) of retired nuclear facilities, where a viable non-destructive evaluation method would increase the overall safety of workers and the environment on and around areas where such facilities exist.

Additionally, this research effort has also helped in contributing to ASTM testing standards, where there was a shortage of experimental protocols for the testing and evaluation of such technologies. Through the series of successful experimentation and close collaboration with Savanah River National Laboratory, the FIU Applied Research Center has not only helped in implementing an operationally relevant approach to conduct a series of tests and evaluation of intumescent polyurethane foam as a permanent foaming fixative under cold (non-radioactive) conditions. ASTM E3191-18 (ASTM International, 2018) was developed under subcommittee E10.03 which deals with the protection for decontamination and decommissioning of nuclear and components. 


\subsection{Future Work}

Future experiments on intumescent foams via an NDE could help in evaluating the size of an anomaly and/or artificialities that can be detected through the use of infrared thermography. Additionally, exploring the feasibility of applying intumescent foams into other areas of varying shapes and contours, such as gloveboxes and pipes with bends, could help to understand variances and nuances that can and may be found whilst using thermal imaging camera. Through experimentation, it was theorized that using multiple thermal imaging devices could help to improve the NDE method for 3-dimensional areas (such as pipes) since the infrared radiation being released during the curing process is being reflected in all directions. 


\section{REFERENCES}

ASTM International. (2018, December). ASTM E3191 - 18, Standard Specification for Permanent Foaming Fixatives Used to Mitigate Spread of Radioactive Contamination. West Conshohocken, Pennsylvania.

Bourbigot, S., Le Bras, M., Duquesne, S., \& Rochery, M. (2004, June 25). Recent Advances for Intumescent Polymers. Macromolecular Materials and Engineering, 289(6), 499-511. doi:10.1002/mame.200400007

Demmer, R., Fox, D., Reese, S., Banford, A., \& Dodds, J. (2017). Fixatives Used for Decommissioning and Maintenance of Radiological Facilities -17537. Retrieved from http://wmsym.org/archives/2017/pdfs/FinalPaper_17537_0109035811.pdf

Duquesne, S., Magnet, S., Jama, C., \& Delobel, R. (2004, March 1). Intumescent paints: fire protective coatings for metallic substrates. Surface and Coatings Technology, 302-307. doi:10.1016/j.surfcoat.2003.10.075

Extech, A FLIR Company. (2015). SDL200: 4-Channel Datalogging Thermometer | Extech Instruments. Retrieved from Extech.com: http://www.extech.com/SDL200/

Extech, A FLIR Company. (2015). TP870: Bead Wire Type K Temperature Probe (-40 to $482 ? \mathrm{~F})$ | Extech Instruments. Retrieved from Extech.com: http://www.extech.com/display/?id=14787

Gharehbagh, A., \& Ahmadi, Z. (2012). Polyurethane Flexible Foam Fire Behavior. doi: $10.5772 / 47965$

International Electrotechnical Commission (IEC). (2013, May 21). Fire hazard testing Part 11-10: Test flames - $50 \mathrm{~W}$ horizontal and vertical flame test methods. International Electrotechnical Commission. Retrieved from https://webstore.iec.ch/publication/2938

Khanna, A. S., \& Puri, R. G. (2016, August 8). Intumescent coatings: A review on recent progress. Journal of Coatings Technology and Research, 14(1), 1-20. doi:10.1007/s11998-016-9815-3

Lazonby, J. (2015). Polyurethanes. Retrieved from Essentialchemicalindustry.org: http://www.essentialchemicalindustry.org/polymers/polyurethane.html

Los Alamos National Laboratory, Operated by Los Alamos National Security, LLC, for the U.S. Department of Energy. (2019). Safeguards and Security Technology Training Program. Retrieved from Lanl.gov: https://www.lanl.gov/org/ddste/aldgs/sst-training/index.php

Lucherini, A., \& Maluk, C. (2019). Intumescent coatings used for the fire-safe design of steel structures: A review. Journal of Constructional Steel Research, 162, 105712. doi:10.1016/j.jcsr.2019.105712 
Nelson, R., Patterson, R., \& VanLuik, A. (2015). The February 2014 Accidents at WIPP 15024 (What Happened and What We Know About Why). WM2015 Conference. Pheonix: U.S. Department of Energy.

Nicholson, J., \& Velten, J. (2017). Evaluation of Environmental Conditions on the Curing Of Commercial Fixative and Intumescent Coatings. doi:10.2172/1404906

Nicholson, J., Peters, B., Wilson, J., \& Washington, A. (2016). FABRICATION AND EVALUATION OF RADIATION HARDENED POLYURETHANE FOAMS FOR $D \& D$ ACTIVITIES. Savannah River National Laboratory.

Sinicrope, J., Shoffner, P., Viera, J., Nuñez, J., \& Simoes-Ponce, T. (2018). Testing and Evaluating Radiological Shielding Foams Resistance to Thermal Stressors. Florida International University. Miami: Applied Research Center.

Yang, R., Hu, W., Xu, L., Song, Y., \& Li, J. (2015). Synthesis, mechanical properties and fire behaviors of rigid polyurethane foam with a reactive flame retardant containing phosphazene and phosphate. Polymer Degradation and Stability, 102-109. doi:10.1016/j.polymdegradstab.2015.10.007 